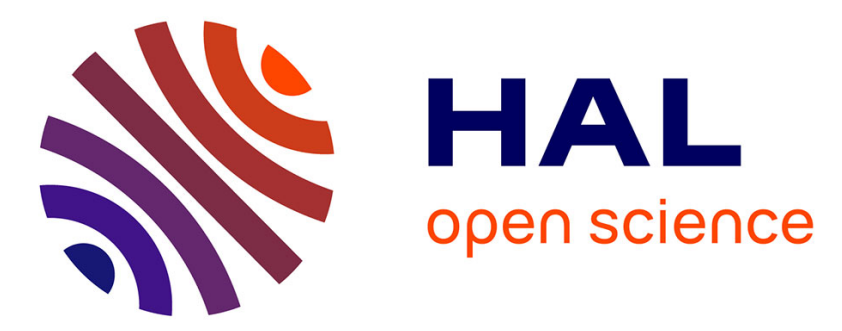

\title{
$\beta$-Cyclodextrin-Based Star Amphiphilic Copolymers: Synthesis, Characterization, and Evaluation as Artificial Channels
}

\author{
Ibrahima Faye, Cécile Huin, Nicolas Illy, Véronique Bennevault, Philippe \\ Guégan
}

\section{To cite this version:}

Ibrahima Faye, Cécile Huin, Nicolas Illy, Véronique Bennevault, Philippe Guégan. $\beta$-CyclodextrinBased Star Amphiphilic Copolymers: Synthesis, Characterization, and Evaluation as Artificial Channels. Macromolecular Chemistry and Physics, 2019, 220 (2), pp.1800308. 10.1002/macp.201800308. hal-02189365

\section{HAL Id: hal-02189365 \\ https://hal.sorbonne-universite.fr/hal-02189365}

Submitted on 19 Jul 2019

HAL is a multi-disciplinary open access archive for the deposit and dissemination of scientific research documents, whether they are published or not. The documents may come from teaching and research institutions in France or abroad, or from public or private research centers.
L'archive ouverte pluridisciplinaire HAL, est destinée au dépôt et à la diffusion de documents scientifiques de niveau recherche, publiés ou non, émanant des établissements d'enseignement et de recherche français ou étrangers, des laboratoires publics ou privés. 


\title{
$\beta$-Cyclodextrin-Based Star Amphiphilic Copolymers: Synthesis, Characterization, and Evaluation as Artificial Channels
}

\author{
Ibrahima Faye, Cécile Huin, Nicolas Illy, Véronique Bennevault, and Philippe Guégan*
}

\begin{abstract}
14-arm amphiphilic star copolymers are synthesized according to different strategies. First, the anionic ring polymerization of 1,2-butylene oxide (BO) initiated by per(2-O-methyl-3,6-di-O-(3-hydroxypropyl))- $\beta$ - $C D\left(\beta-\mathrm{CD}^{\prime} \mathrm{OH}_{14}\right)$ and catalyzed by $\mathrm{t}-\mathrm{BuP}_{4}$ in DMF is investigated. Analyses by NMR and SEC show the well-defined structure of the star $\beta$-CD'-PBO ${ }_{14}$. To obtain a 14-arm poly(butylene oxide- $b$-ethylene oxide) star, a Huisgen cycloaddition between an $\alpha$-methoxy- $\omega$-azidopoly(ethylene oxide) and the $\beta$-CD'-PBO ${ }_{14}$, whose endchains are beforehand alkyne-functionalized, is performed. In parallel, 14-arm star copolymers composed of butylene oxide- $b$-glycidol arms are successfully synthesized by the anionic polymerization of ethoxyethylglycidyl ether (EEGE) initiated by $\beta$-CD'-PBO ${ }_{14}$ with $\mathrm{t}-\mathrm{BuP}_{4}$. The deprotection of EEGE units is then performed to provide the polyglycidol blocks. These amphiphilic star polymers are evaluated as artificial channels in lipid bilayers. The effect of changing a PEO block by a polyglycidol block on the insertion properties of these artificial channels is discussed.
\end{abstract}

\section{Introduction}

Star polymers have only one branching point per macromolecule, unlike graft copolymers, dendrimers, and hyperbranched polymers, which makes them the most basic form among branched polymers. They consist of at least three linear macromolecular chains of comparable lengths radiating from a central nucleus, called core. They were first obtained by living anionic polymerization in the 1950s and have been the subject of extensive research since then because of their topological structures

Dr. I. Faye, Dr. N. Illy, Dr. V. Bennevault, Prof. P. Guégan

Team Chimie des Polymères, Institut Parisien de Chimie Moléculaire (UMR-CNRS 8232)

Sorbonne Université

4 Place Jussieu, 75005 Paris, France

E-mail: philippe.guegan@sorbonne-universite.fr

Dr. I. Faye, Dr. C. Huin

LAMBE, CEA, CNRS

University of Evry

University of Paris-Saclay

91025 Evry, France

Dr. V. Bennevault

University of Evry

91025 Evry, France

The ORCID identification number(s) for the author(s) of this article can be found under https://doi.org/10.1002/macp.201800308. and their unique chemical and physical properties, that is, encapsulation abilities due to their 3D globular structures. ${ }^{[1,2]}$ Star polymers are often synthesized by one of the following four strategies ${ }^{[3,4]}$ : "armfirst," $"[5]$ "core-first," $[6,7]$ "coupling-onto,,$[8]$ and "iterative methodology"[9] by radical, metal alkylidene, anionic, and cationic polymerization processes. Each of these approaches has certain advantages and disadvantages that must be taken into consideration according to the desired macromolecular architecture and involved chemistry. However, it seems that "corefirst" method by anionic polymerization is among the most suitable strategies to synthesize well-defined star architectures. ${ }^{[10-12]}$ This technique enables exquisite control over the architecture and molar mass distribution and also allows the synthesis of star block copolymers. This synthesis route requires a well-defined multifunctional core able to provide fast initiation.

Phosphazene bases, a new category of organic catalysts, provide good control of anionic polymerizations. ${ }^{[13-15]}$ They make it possible to exempt from organometallic initiators, a residual presence of which may be detrimental to certain uses (biomedical, electronics, etc.). Generally, phosphazene bases significantly improve the nucleophilicity of the initiator/ chain end, by complexation with the counterion (e.g., proton or lithium cation), resulting in a rapid and usually controlled anionic polymerization. ${ }^{[14]}$ Their complexing capacity can be used in the case of copolymerization for block copolymers for which the nature of the counterion is unsuitable for the polymerization of the second monomer, ${ }^{[16]}$ or to polymerize low reactive monomers. ${ }^{[17]}$

Regarding the core of star polymers within a context of sustainable chemistry, cyclodextrins are good candidates due to their high functionality and their natural origin. Cyclodextrins are biocompatible and biodegradable cyclic oligosaccharides derived from enzymatic degradation of starch. The three most common native cyclodextrins, $\alpha-, \beta-, \gamma$-cyclodextrins, are composed, respectively, of six, seven, or eight $\alpha$-D-glucopyranose units linked together by $\alpha-1,4$ bonds. Their 3D structure appears in the form of a truncated cone with primary and secondary hydroxyls located on the narrow and the wider faces (Figure 1). Their torus shape gives them complexing properties which allows them to be used in various applications such 


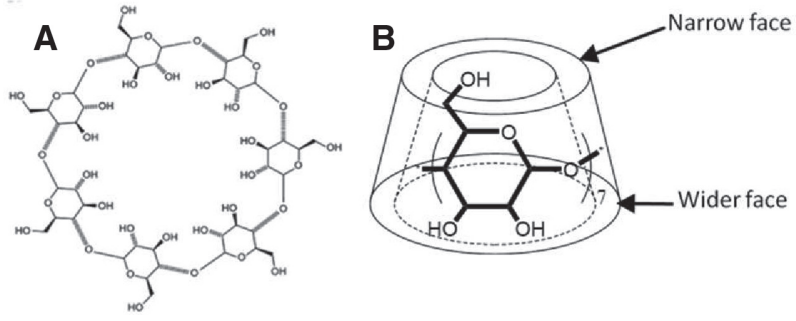

Figure 1. A) Chemical structure and B) truncated cone shape of $\beta$-cyclodextrin $(\beta-C D)$.

as food, ${ }^{[18]}$ pharmaceuticals, ${ }^{[19]}$ cosmetics, ${ }^{[20]}$ and catalysis. ${ }^{[21]}$ Some articles describe the use of cyclodextrins as a core of star macromolecular architectures for different applications such as drug and gene delivery, ${ }^{[22,23]}$ nanocrystal clusters, ${ }^{[24]}$ compatibilization, ${ }^{[25]}$ thermoresponsive self-assemblies, ${ }^{[26]}$ and artificial channels. ${ }^{[27-29]}$ Artificial channels are used in filtration processes $^{[30]}$ or as antibiotics. ${ }^{[31]}$

In this study, we report the synthesis of regular 14-branched star homopolymers and copolymers with a $\beta$-cyclodextrin core by anionic ring-opening polymerization of epoxides. The arms of these star structures are made of butylene oxide units for the homopolymers and butylene oxide-ethylene oxide or butylene oxide-glycidol units for the copolymers. A "core-first" strategy was used to synthesize the homopolymers. Then, the latter were used either in a "grafting-onto" strategy or as macroinitiator in a "core-first" process in order to synthesize the star block copolymers. All the synthesized polymers were evaluated as artificial channels by electric measurements, to determine the interactions between these molecules and a model lipid bilayer. Analysis of the variation of the current through the lipid membranes allowed to determine the nature of the species interacting with the bilayer and to connect these interactions with the molecular structure of the star polymers.

\section{Experimental Section}

\subsection{Materials}

$\beta$-cyclodextrin (Roquette, France) was recrystallized in water and dried for 2 days at $100{ }^{\circ} \mathrm{C}$ under vacuum, prior to use. The per(2-O-methyl-3,6-di-O-(3-hydroxypropyl))- $\beta$-CD, named $\beta$-CD'OH ${ }_{14}$, was synthesized in five steps, as described in the Supporting Information (Scheme S1 steps 1-5, Supporting Information). Phosphazene base $\mathrm{tBuP}_{4}$ solution $\left(0.8 \mathrm{~mol} \mathrm{~L}^{-1}\right.$ in hexane, Sigma-Aldrich) was used as received. Butylene oxide (BO) (1,2-epoxybutane, $\geq 99.9 \%$, Sigma-Aldrich), $N, N$ dimethylformamide (DMF) (99.9\%, VWR) were distilled three times over $\mathrm{CaH}_{2}$. Tetrahydrofuran (THF) (99.9\%, VWR) and toluene (99.9\%, VWR) were dried on a sodium/benzophenone mixture until a persistent blue color and distilled. $\alpha$-Methoxy$\omega$-hydroxy-poly(ethylene oxide) (200 and $500 \mathrm{~g} \mathrm{~mol}^{-1}$, SigmaAldrich) was dried at $100{ }^{\circ} \mathrm{C}$ under vacuum for $12 \mathrm{~h}$ and was modified according to the procedures described in Sections SII, SIII, SIV, Supporting Information. Copper (nanopowder,
40-60 nm particle size, 99.9\%) was purchased at Sigma-Aldrich and used as received. Ethoxyethylglycidyl ether (EEGE) was synthesized according to a procedure described by Fitton ${ }^{[32]}$ with some slight adjustments (Section SVI, Supporting Information). Other reactants were used as received. The dialysis membrane (cut-off molar mass: $1000 \mathrm{~g} \mathrm{~mol}^{-1}$ ) was purchased from Interchim.

\subsection{Instruments}

${ }^{1} \mathrm{H}(300 \mathrm{MHz})$ and ${ }^{13} \mathrm{C}(75.43 \mathrm{MHz})$ NMR spectra were recorded on a Bruker Avance 300 spectrometer at $25{ }^{\circ} \mathrm{C}$. The software used for data analysis was Topspin. For the diffusionordered spectroscopy (DOSY) experiments, the maximum field gradient strength was calibrated using a homemade Plexiglass phantom $(8 \mathrm{~mm} \pm 0.01$ length and a width equal to the inner diameter of the NMR tube) inserted in a $\mathrm{H}_{2} \mathrm{O}$ filled NMR tube and using the pulse program calibgp. ${ }^{[33]}$ The linear plot of the obtained gradient strengths against the gradient strength setting (GPZ1) gave a maximum field gradient strength equal to $56.8 \mathrm{G} \mathrm{cm}^{-1}$. The temperature calibration of the spectrometer was performed with a sample of $100 \%$ $\mathrm{CH}_{3} \mathrm{OH}$ in the temperature range between 298 and $313 \mathrm{~K}$. The accuracy of the calibrations was checked by measuring the self-diffusion coefficient of a mixture $\mathrm{H}_{2} \mathrm{O} / \mathrm{D}_{2} \mathrm{O}(10 \% / 90 \%$ in moles) at $25^{\circ} \mathrm{C} .^{[34]}$

Size exclusion chromatography (SEC) experiments were performed in DMF (with $\mathrm{LiBr}, 1 \mathrm{~g} \mathrm{~L}^{-1}$ ) at $60{ }^{\circ} \mathrm{C}$ with a flow rate of $0.8 \mathrm{~mL} \mathrm{m^{-1 }}$ using two PSS Gram $1000 \AA$ columns $\left(8 \times 300 \mathrm{~nm}\right.$; separation limits: $\left.1-1000 \mathrm{~kg} \mathrm{~mol}^{-1}\right)$ and one PSS gram $30 \AA \AA\left(8 \times 300 \mathrm{~nm}\right.$; separation limits: $\left.0.1-10 \mathrm{~kg} \mathrm{~mol}^{-1}\right)$ coupled with a differential refractive index (RI) detector. The molar masses of the star polymers were determined with a calibration curve based on narrow poly(methyl methacrylate) standards (from Polymer Standard Services) using the RI detector.

\subsection{Polymerizations}

\subsubsection{Synthesis of 14-Arm Poly(Butylene Oxide) Star Polymer $\left(\beta-C D^{\prime}-P B O_{14}\right)$}

Ring-opening polymerization of $\mathrm{BO}$, initiated by the $\mathrm{CD}$ derivative, $\quad$ per(2-O-methyl-3,6-di-O-(3-hydroxypropyl))- $\beta$-CD $\left(\beta\right.$-CD'OH$\left.{ }_{14}\right)$, was performed as follows: $\beta$ - $\mathrm{CD}^{\prime} \mathrm{OH}_{14}$ was introduced in the reaction flask and dried for $12 \mathrm{~h}$, under dynamic vacuum, at $120{ }^{\circ} \mathrm{C}$. Then, in a glovebox, the $\mathrm{CD}$ derivative was dissolved in the minimum of freshly dried DMF. Dried toluene was added and stirred during $8 \mathrm{~h}$. Solvents were evaporated and the CD derivative was dried again under vacuum at $120{ }^{\circ} \mathrm{C}$ for $12 \mathrm{~h}$. Then, $\beta-\mathrm{CD}^{\prime} \mathrm{OH}_{14}$ was dissolved in dried DMF under Argon, and $\mathrm{tBuP}_{4}$ and $\mathrm{BO}$ were added in the reaction flask and polymerization carried out at $25^{\circ} \mathrm{C}$. After $72 \mathrm{~h}$, the reaction was quenched with acetic acid (30 min of stirring). After evaporation of DMF, the product was solubilized in pentane and washed three times with acetonitrile to remove the phosphazene base. After evaporation of pentane and drying under vacuum, a brown oil was obtained $\left(\beta\right.$-CD'-PBO $\left.{ }_{14}\right)$. 


\subsubsection{Synthesis of 14-Arm Poly (Butylene Oxide-b-Ethylene Oxide) Star Copolymer $\left(\beta-C D^{\prime}-P(B O-b-E O){ }_{14}\right)$}

$\beta$-CD'- $\mathrm{P}(\mathrm{BO}-b-\mathrm{EO})_{14}$ was synthesized by the "grafting-onto" strategy using two synthetic routes. Route 1 . In a $100 \mathrm{~mL}$ round-bottom flask, $100 \mathrm{mg}$ of $\beta$-CD'- $\mathrm{PBO}_{14}(0.2 \mathrm{mmol} \mathrm{OH}$ functions), dried under vacuum at $80{ }^{\circ} \mathrm{C}$ overnight, were dissolved in $5 \mathrm{~mL}$ of dried DMF. NaH (1.6 mmol, 8 eq. per $\mathrm{OH}$ ), freshly washed with pentane, was added to the solution, at $0{ }^{\circ} \mathrm{C}$, and the suspension was stirred for $12 \mathrm{~h}$ at $25^{\circ} \mathrm{C}$. Then, $\alpha$-methoxy- $\omega$-mesylpoly(ethylene oxide) mPEO-Ms ( $2 \mathrm{mmol}$, 10 eq. per $\mathrm{OH}-200$ and $500 \mathrm{~g} \mathrm{~mol}^{-1}$, synthesis described in Section SII, Supporting Information), dried at $80^{\circ} \mathrm{C}$ overnight, was added and left for 7 days under stirring at $25^{\circ} \mathrm{C}$. The reaction medium was then precipitated in $50 \mathrm{~mL}$ of water. After filtration, the precipitate was dissolved in $\mathrm{CHCl}_{3}$. The organic phase was dried on $\mathrm{MgSO}_{4}$, filtered, and concentrated under vacuum. The polymer was then dried under vacuum, at $80^{\circ} \mathrm{C}$, for $12 \mathrm{~h}$, and characterized by ${ }^{1} \mathrm{H}$ NMR.

Route 2. Coupling was performed by click chemistry. First, the propargylation of $\beta$-CD'- $\mathrm{PBO}_{14}$ was performed (synthesis described in Section SV, Supporting Information), followed by the Huisgen cycloaddition with a $\alpha$-methoxy- $\omega$ azidopoly(ethylene oxide) $\mathrm{mPEO}_{500}-\mathrm{N}_{3}$ (synthesis described in Supporting Information SIV). In a $100 \mathrm{~mL}$ round-bottom flask, $50 \mathrm{mg}$ of $\beta$-CD'-PBO ${ }_{14}$-propargyl $(0.1 \mathrm{mmol}$ propargyl functions), dried at $80^{\circ} \mathrm{C}$ under vacuum overnight, were dissolved in $2 \mathrm{~mL}$ of dried DMF. $\mathrm{mPEO}_{500}-\mathrm{N}_{3}(0.4 \mathrm{mmol}$, 4 eq. per propargyl) and copper $(0.2 \mathrm{mmol}, 2$ eq. per propargyl) were added. The reaction was conducted at $50^{\circ} \mathrm{C}$ for $48 \mathrm{~h}$. At the end of the reaction, DMF was evaporated under vacuum. The resulting product was dissolved in $25 \mathrm{~mL}$ of water and the solution was centrifuged and filtered to remove the copper nanoparticles (CuNPs). Then, the solution was dialyzed against water for $72 \mathrm{~h}$ (cut-off molar mass: $1000 \mathrm{~g} \mathrm{~mol}^{-1}$ ). The aqueous phase was then freezedried. Yellowish oil was obtained with a yield of $78 \% .{ }^{1} \mathrm{H}$ NMR, DOSY NMR, and SEC were performed to analyze the product.

\subsubsection{Synthesis of 14-Arm Poly (Butylene Oxide-b-Ethoxyethylglycidyl} Ether) Star Copolymer ( $\beta$-CD'-P(BO-b-EECE) 14 )

$\beta$-CD'-P(BO-b-EEGE) $)_{14}$ was synthesized using a "core-first" strategy. $\beta$-CD'- $\mathrm{PBO}_{14}$ was introduced in a reactor and dried for $12 \mathrm{~h}$ under vacuum at $120^{\circ} \mathrm{C}$. After complete dissolution of the macroinitiator in dried toluene (in a glovebox), $\mathrm{tBuP}_{4}$ (0.2 eq. per $\mathrm{OH}$ functions), and EEGE were added in the reactor. Polymerization was conducted at room temperature for $72 \mathrm{~h}$. Then, toluene was evaporated. The product was dissolved in $100 \mathrm{~mL}$ of diethylether and washed with $3 \times 100 \mathrm{~mL}$ of water. The organic phase was concentrated and the resulting product was dried for $12 \mathrm{~h}$ at $50^{\circ} \mathrm{C}$ (yield: $90 \%$ ).

\subsubsection{Synthesis of 14-Arm Poly (Butylene Oxide-b-Glycidol) Star Copolymer ( $\left.\beta-C D^{\prime}-P(B O-b-G E)_{14}\right)$}

In a $100 \mathrm{~mL}$ round-bottom flask, $100 \mathrm{mg}$ of $\beta$-CD'-P(BO-bEEGE) ${ }_{14}$ were dissolved in $10 \mathrm{~mL}$ of formic acid and stirred at $25{ }^{\circ} \mathrm{C}$ for $24 \mathrm{~h}$. After evaporation of the reaction medium, the product was dissolved in $2 \mathrm{~mL}$ of THF and $4 \mathrm{~mL}$ of $\mathrm{KOH}$ (2 mol L-1 in $\mathrm{H}_{2} \mathrm{O}$ ) were added, the reaction being conducted at $50{ }^{\circ} \mathrm{C}$ for $48 \mathrm{~h}$. Then, $\mathrm{HCl}\left(2 \mathrm{~mol} \mathrm{~L}^{-1}\right.$ in $\left.\mathrm{H}_{2} \mathrm{O}\right)$ was added until neutralization. After solvents' evaporation, the product was dissolved in $10 \mathrm{~mL}$ of water and dialyzed against water for $48 \mathrm{~h}$ (cut-off molar mass: $1000 \mathrm{~g} \mathrm{~mol}^{-1}$ ). The aqueous phase was freeze-dried and $\beta$-CD'-P(BO-b-GE $)_{14}$ was obtained with a yield of $70 \%$.

\subsection{Characterization of the Artificial Channels}

A film of diphytanoylphosphatidylcholine $\left(10 \mathrm{mg} \mathrm{mL}^{-1}\right.$ in decane) was spread across a $150 \mu \mathrm{m}$ wide hole, separating two chambers of a measurement device. Each chamber contained $1 \mathrm{~mL}$ of a $1 \mathrm{~m} \mathrm{KCl}, 5 \mathrm{~mm}$ HEPES (4-(2-Hydroxyethyl) piperazine-1-ethanesulfonic acid) buffer solution $(\mathrm{pH}=7)$. After thinning the decane film, in order to get a planar bilayer of appropriate capacitance, star polymers were added in both chambers at a controlled concentration (all the star polymers were dissolved in THF, in order to facilitate the manipulation of the hydrophobic compounds). A voltage was then applied to the lipid bilayer and electric current measurements were performed. The ionic current through the membrane was measured with a BLM 120 amplifier (Biologic). Data were acquired at $1500 \mathrm{~Hz}$ and filtered at $300 \mathrm{~Hz}$ with the Measurement Computing Digitizer.

\section{Results and Discussion}

\subsection{Polymerization of 1,2-Butylene Oxide (BO) Initiated by Per(2-O-Methyl-3,6-di-O-(3-Hydroxypropyl))- $\beta-C D$}

Polymerizations of $\mathrm{BO}$ were performed in DMF at room temperature with $\mathrm{tBuP}_{4}$ as catalyst and per(2-O-methyl-3,6di-O-(3-hydroxypropyl))- $\beta$-CD as initiator (Scheme 1). DMF was chosen as polymerization solvent because, out of water, DMF is the only solvent that solubilizes the multifunctional initiator. As far as we know, only one work on the synthesis of $\mathrm{PBO}$ star polymers, in the presence of $\mathrm{tBuP}_{4}$, was reported in the literature, ${ }^{[35]}$ allowing the synthesis of four-arm star polymers.

When using a multifunctional initiator in anionic polymerization, the dissociation equilibrium between free ions and aggregates tended to move toward the aggregates during the exchange reactions between the dormant species (alcohols) and the active species (alkoxides). ${ }^{[36]}$ Huin et al. ${ }^{[6]}$ reported that during the polymerization of ethylene oxide initiated by cyclodextrins, a small amount of diphenylmethylpotassium (DPMK) as catalyst is necessary and allows a control of the polymerization reactions. In our case, the polymerizations were carried out with small amounts of deprotonating agent $\left(\mathrm{tBuP}_{4}\right)$ in order to avoid any phenomenon of aggregations which are in part responsible for the slowness of the polymerization reactions. ${ }^{[36-38]}$ Results are reported in Table 1.

Low $X_{\mathrm{n}}$ were targeted for analysis purpose and for the studies of lipid bilayer-polymer interactions later on. ${ }^{[27,28]}$ The 


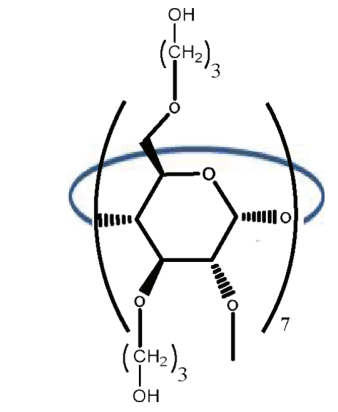

14-functional macroinitiator

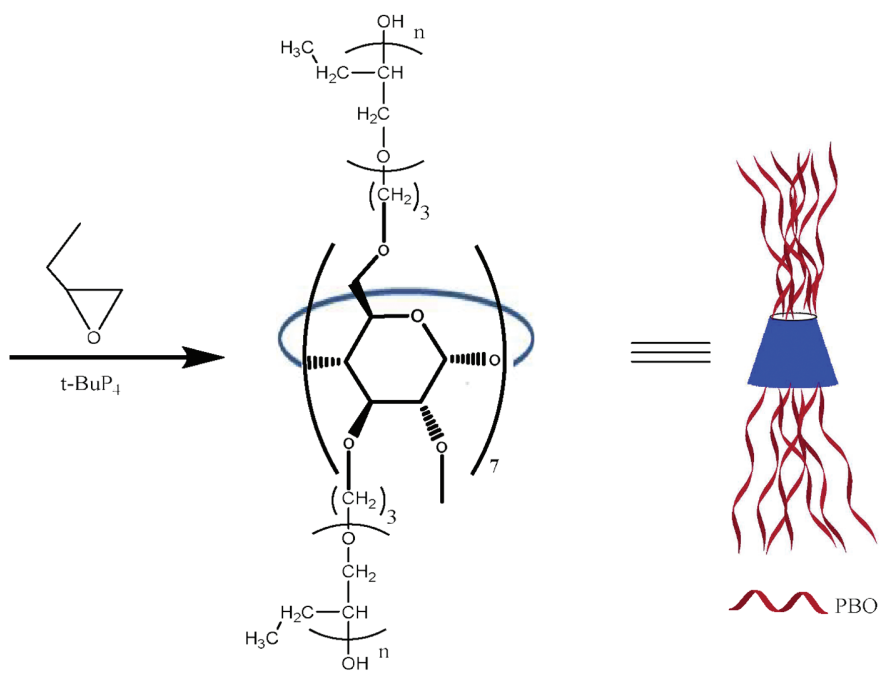

Star polymer with $\mathrm{PBO}$ arms and $\beta-\mathrm{CD}$ as core

Scheme 1. Pathway route for synthesis of $\beta-\mathrm{CD}^{\prime}-\mathrm{PBO}_{14}$ star polymer.

conversion of the monomer was determined by ${ }^{1} \mathrm{H}$ NMR. A full conversion was obtained after $72 \mathrm{~h}$ of polymerization for all the runs. The SEC traces of the products displayed symmetrical monodisperse peaks with a dispersity $(\mathrm{D})$ ranging from 1.04 to 1.10. Figure 2 shows the SEC trace of run 4.

The ${ }^{1} \mathrm{H}$ NMR spectrum of run 4 is given in Figure 3. The major signals at 0.9 and $1.5 \mathrm{ppm}$ were assigned to methyl (d) and methylene (c) protons of the $\mathrm{PBO}$ chains. The presence of the $\beta$-CD core was demonstrated by the signals of the anomeric protons (1) at $5.10 \mathrm{ppm}$ and the protons of the methylene group (8) at $1.80 \mathrm{ppm}$. The major signal in the range $3.00-4.00 \mathrm{ppm}$ was attributed to the other protons of the initiator and polymer. No signal of allylic protons derived from chain-transfer reaction was observed in the 5.30-6.50 ppm range. These results demonstrate that the polymerization was performed without side reaction.

We also determined on this spectrum (Figure 3) an integration ratio of 42.14 between the protons of the methyl groups (d) of the POB chains at $0.90 \mathrm{ppm}$ and the anomeric protons (1) of the initiator. This afforded an NMR number average molar

Table 1. Polymerizations of $\mathrm{BO}$, initiated by $\beta-\mathrm{CD}^{\prime} \mathrm{OH}_{14}$, in the presence of $\mathrm{tBuP}_{4}$ in DMF, at $25^{\circ} \mathrm{C}$, for $72 \mathrm{~h}$, with $[\mathrm{BO}]=3 \mathrm{M}$.

\begin{tabular}{|c|c|c|c|c|c|c|c|}
\hline \multirow[t]{2}{*}{ Run } & \multirow[t]{2}{*}[\mathrm{BO}]{$/[\mathrm{OH}] /\left[\mathrm{P}_{4}\right]^{\mathrm{a})}$} & \multirow{2}{*}{$\begin{array}{c}\left.\overline{M n}_{t^{t h}}{ }^{b}\right) \\
{\left[\mathrm{g} \mathrm{mol}^{-1}\right]}\end{array}$} & \multicolumn{3}{|c|}{ NMR } & \multicolumn{2}{|c|}{ SEC } \\
\hline & & & $\begin{array}{c}\text { Conversion }^{c)} \\
{[\%]}\end{array}$ & $\begin{array}{c}\overline{\mathrm{Mn}}^{\mathrm{c})} \\
{\left[\mathrm{g} \mathrm{mol}^{-1}\right]}\end{array}$ & $\begin{array}{c}X \mathrm{X} \\
\mathrm{arm}^{\mathrm{c})}\end{array}$ & $\bigoplus^{d)}$ & $\begin{array}{c}\overline{M n^{\mathrm{d}}} \\
{\left[\mathrm{g} \mathrm{mol}^{-1}\right]}\end{array}$ \\
\hline 1 & $7 / 1 / 0.2$ & 9100 & 100 & 10000 & 8 & 1.10 & 8640 \\
\hline 2 & $6 / 1 / 0.2$ & 8100 & 100 & 8100 & 6 & 1.10 & 7000 \\
\hline 3 & $6 / 1 / 0.2$ & 8100 & 100 & 8100 & 6 & 1.04 & 8250 \\
\hline 4 & $6 / 1 / 0.2$ & 8100 & 100 & 9100 & 7 & 1.05 & 7400 \\
\hline
\end{tabular}

a) Molar ratio Monomer/Initiator/Phosphazene Base; b) $\overline{M n}$ theoretical = Conversion (NMR) $\times$ Monomer molar eq. $\times M$ (monomer) $+M$ (initiator); ${ }^{c}$ Determined by ${ }^{1} H$ NMR; ${ }^{d}$ SECC in DMF, calibration with PMMA standards. mass $\bar{M}_{\mathrm{n}}$ of $9100 \mathrm{~g} \mathrm{~mol}^{-1}$. Assuming that all polymer chains grew at the same speed, this molar mass was equivalent to 7 units in average of $\mathrm{BO}$ per arm which agreed with the theoretical molar masses predicted from the initial ratio of $[\mathrm{BO}]_{0} /$ $[\mathrm{OH}]_{0}$ and monomer conversion.

In the anionic polymerization, a defect in the drying of one of the components of the reaction mixture (initiator, catalyst, monomer, and solvent) can lead to the formation of polymer chains resulting from initiation by residual water, conducting to a mixture of star and linear polymers. Quantitative ${ }^{13} \mathrm{C}$ NMR analysis was made (Figure 4) in order to alleviate the presence of linear polymer.

The ${ }^{13} \mathrm{C}$ NMR spectrum of run 4 confirmed the SEC analysis and the absence of linear PBO, thanks to the absence of signal around 60-63 ppm. No methylene carbon bearing a hydroxyl function was observed, indicating that no initiation by water occurred. All the signals were attributed and by comparing the integrations of carbons (8), belonging to the $\beta$ - $\mathrm{CD}$ derivative, at $31 \mathrm{ppm}$, and of carbons (d), belonging to the BO units, at $10 \mathrm{ppm}$, it was possible to determine $\bar{M}_{\mathrm{n}}$. The obtained value was in accordance with ${ }^{1} \mathrm{H}$ NMR and SEC results.

The synthesized polymers were characterized by a good correlation between theoretical and experimental average molar masses and narrow dispersities $(\boxplus \leq 1.10)$, suggesting a controlled polymerization. To ascertain the star architecture of the polymers, DOSY NMR of the macroinitiator and polymers were performed. This NMR technique at two dimensions allows the characterization of mixtures of molecules and macromolecules by measuring self-diffusion coefficients. ${ }^{[39,40]}$ As signals belonging to the same macromolecule have the same diffusion coefficients, it was possible to determine whether the $\mathrm{PBO}$ 


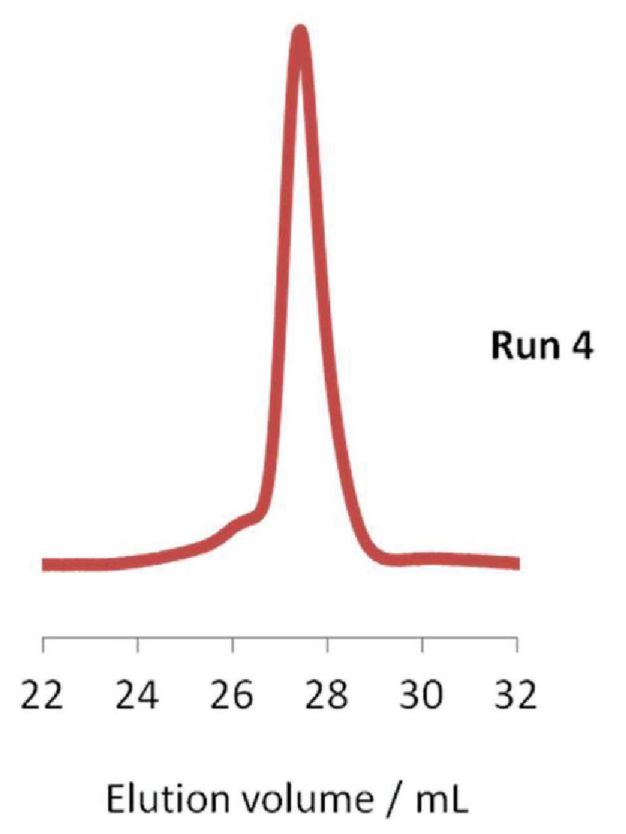

Figure 2. SEC chromatogram of run 4 (Table 1) in DMF.

chains were covalently linked to the $\beta$-CD core. Table 2 gathers the diffusion coefficients of analyzed products.

Polymers with comparable molar masses had similar diffusion coefficients, while the diffusion coefficient of the multifunctional initiator was higher, in accordance with its lower hydrodynamic volume. For each polymer, regardless of the NMR signal considered, we obtained the same diffusion coefficient, as evidenced by the low value of the standard deviation. This analysis revealed that the cyclodextrin core and the polymer chains diffuse at the same speed and thus confirmed the star structure of the polymers.

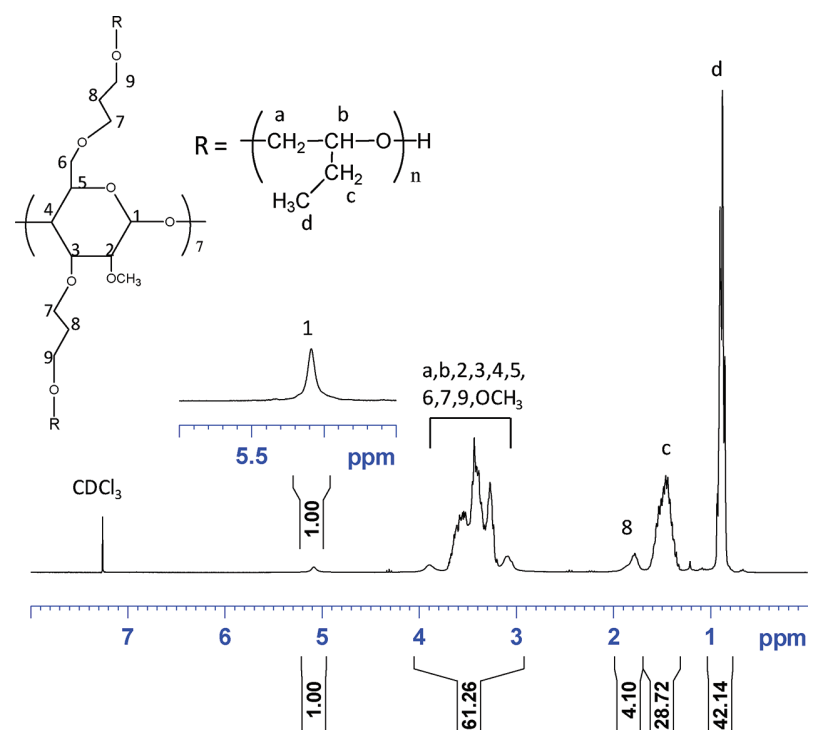

Figure 3. ${ }^{1} \mathrm{H}$ NMR spectrum of run 4 (Table 1) in deuterated chloroform.

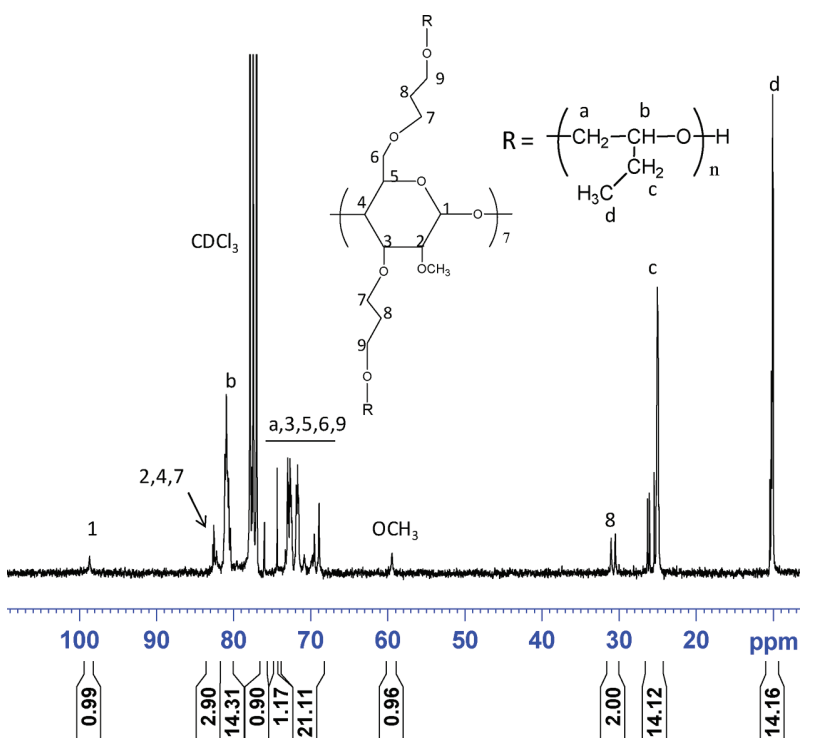

Figure 4. Quantitative ${ }^{13} \mathrm{C}$ NMR spectrum of run 4 (Table 1 ) in deuterated chloroform.

\subsection{Synthesis of Amphiphilic Star Copolymers}

\subsubsection{Synthesis of 14-Arm Poly (Butylene Oxide-b-Ethylene Oxide) Star Copolymer ( $\beta$-CD'-P(BO-b-EO) $\left.{ }_{14}\right)$}

The syntheses of this kind of star-shaped copolymers were carried out by "grafting-onto" method either by nucleophilic substitution, or by click chemistry. This strategy prevented from polymerizing ethylene oxide. For nucleophilic substitution, the secondary hydroxyl functions at the $\beta$-CD'- $\mathrm{PBO}_{14}$ star polymer end-chains were reacted with $\mathrm{MPEO}$ derivatives (mPEO-iodide or mPEO-mesylate) as substrates in the presence of a strong base (sodium hydride). Better results were obtained with mPEO-mesylate. Indeed, mesyl group is a better leaving group than iodide. Nevertheless, whatever the experimental conditions used, a quantitative coupling was not obtained, the maximum substitution of hydroxyl groups being $55 \%$. This partial modification could be due to steric hindrance generated by the first grafted macromolecules, which constitutes the main disadvantage of the "grafting-onto" method in the synthesis of star polymers. ${ }^{[4]}$ This steric hindrance seems to be confirmed by the fact that better functionalization was obtained with $\mathrm{mPEO}_{200}$ than $\mathrm{mPEO}_{500}$.

Table 2. Diffusion coefficients of different compounds, determined by DOSY NMR in DMF- $\mathrm{d}_{7}$ at $25^{\circ} \mathrm{C}$.

\begin{tabular}{lccc}
\hline Product & Compound & $\overline{\mathrm{Mn}} \mathrm{SEC}\left[\mathrm{g} \mathrm{mol}^{-1}\right]$ & $\mathrm{D}\left[\mathrm{m}^{2} \mathrm{~s}^{-1}\right]$ \\
\hline Macroinitiator & $\beta$ - $\mathrm{CD}^{\prime} \mathrm{OH}_{14}$ & 2044 & $(1.75 \pm 0.02) \times 10^{-10}$ \\
$\beta$-CD'-PBO & & 7000 & $(1.23 \pm 0.10) \times 10^{-10}$ \\
$\beta$-CD'-PBO & Run 2 & 8250 & $(1.32 \pm 0.05) \times 10^{-10}$ \\
$\beta$ - CD' $^{\prime}-\mathrm{PBO}_{14}$ & Run 3 & 7400 & $(1.14 \pm 0.06) \times 10^{-10}$ \\
\hline
\end{tabular}




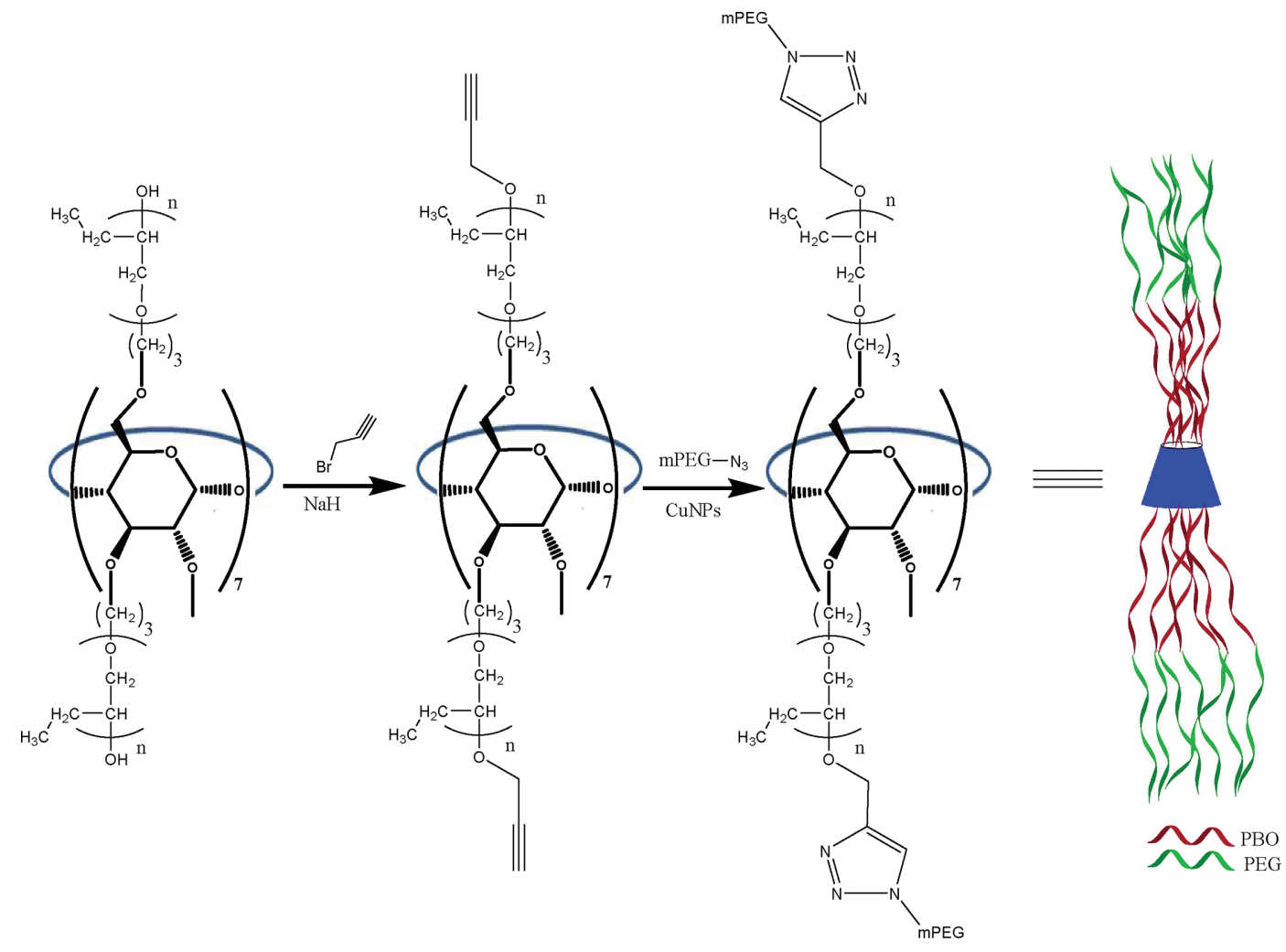

Amphiphilic star copolymer with beta-CD as core

Scheme 2. Synthetic route for $\beta$-CD'-P(BO-b-EO) ${ }_{14}$ star copolymer by click chemistry.

A last strategy using a copper-catalyzed azide-alkyne cycloaddition (CuAAC) was investigated. Huisgen reaction is used extensively to design polymers. ${ }^{[41,42]}$ First the PBO chains were functionalized with propargyl groups (Section SV, Supporting Information), then the propargyl end-chains were coupled with mPEO-N ${ }_{3}\left(500 \mathrm{~g} \mathrm{~mol}^{-1}\right)$ in the presence of CuNPs (Scheme 2). CuNPs are non-toxic, environmentally friendly, highly stable, and recyclable. ${ }^{[41,43-45]}$ This reaction allowed us to obtain star copolymers having $\mathrm{P}(\mathrm{BO}-b$-EO) branches with a quantitative coupling and high yield.

Figure 5 shows ${ }^{1} \mathrm{H}$ NMR spectrum of the corresponding copolymer. In this spectrum, no signal at $2.35 \mathrm{ppm}$ belonging to propargylic groups was observed, whereas the presence of a signal at $7.65 \mathrm{ppm}$ corresponding to the protons (f) of the triazole rings was witnessed. The integration of the protons (f) was 1.94 instead of 2, when the integration of the anomeric protons (1) was set to 1 , which is in the error range of NMR. This result was in line with an efficient and quantitative coupling.

A superposition of the SEC chromatograms of the star homopolymer (run 4, Table 1) and the obtained star copolymer is provided in Figure 6.
A shift toward the high molar masses of the SEC chromatogram of $\beta$-CD'-P(BO- $b$-EO $)_{14}$ relative to the chromatogram of $\beta$-CD'- $\mathrm{PBO}_{14}$ was observed, in agreement with modification of $\beta$-CD'-PBO 14 . We also observed a population with a lowest

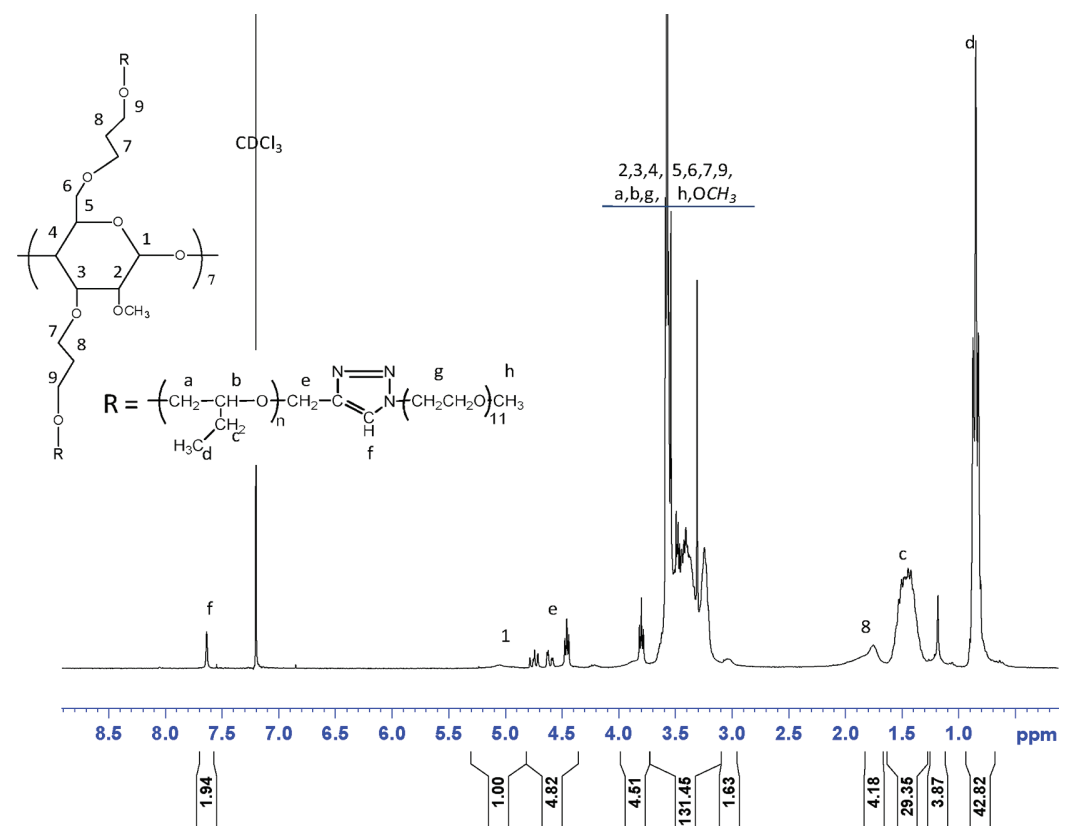

Figure 5. 'H NMR spectrum of $\beta$-CD'-P(BO- $b$-EO $)_{14}$ star copolymer in deuterated chloroform. 


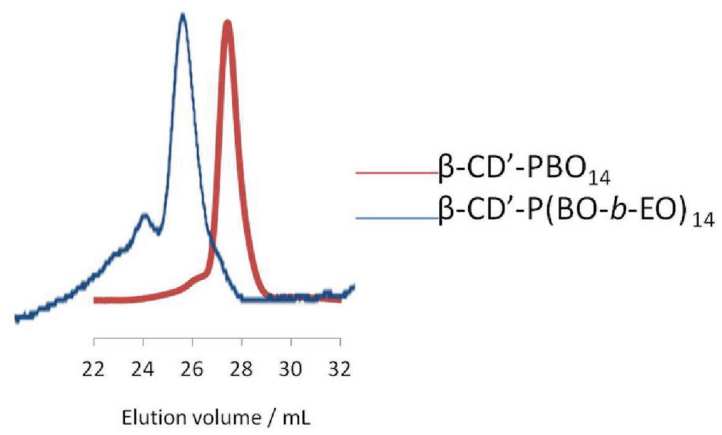

Figure 6. Superposition of $\beta-\mathrm{CD}^{\prime}-\mathrm{PBO}_{14}$ and $\beta-\mathrm{CD}$ '-P(BO- $b$-EO $)_{14} \mathrm{SEC}$ chromatograms in DMF.

elution volume that we attributed to aggregates. Indeed, the star polymers aggregate to form large supramolecular structures. ${ }^{[46,47]}$ The star architecture was confirmed by DOSY NMR in deuterated chloroform. All the signals broadcasted at the same speed $\left(\mathrm{D}=1.03 \pm 0.04 .10^{-10} \mathrm{~m}^{2} \mathrm{~s}^{-1}\right)$ as shown by the pseudo 2D (Figure 7). The low value of the standard deviation indicated a well-defined star structure.

\subsubsection{Synthesis of 14-Arm Poly (Butylene Oxide-b-Glycidol) Star Copolymer $\left(\beta-C D^{\prime}-P(B O-b-G E)_{14}\right)$}

The polymerization of glycidol leads to hyperbranched oligomers because of a repetition of intra- and intermolecular transfer reactions on the primary alcohol. The only way to obtain purely linear polyglycidol is via protected monomers and subsequent deprotection of the hydroxyl groups after polymerization. ${ }^{[48,49]}$ Ethoxyethyl is one of the most used protective group and leads to EEGE (Scheme 3).

Taton $^{[50]}$ was the first to report the synthesis of linear polyglycidol with $\bar{M}_{\mathrm{n}}$ up to $30000 \mathrm{~g} \mathrm{~mol}^{-1}$ via anionic ring-opening

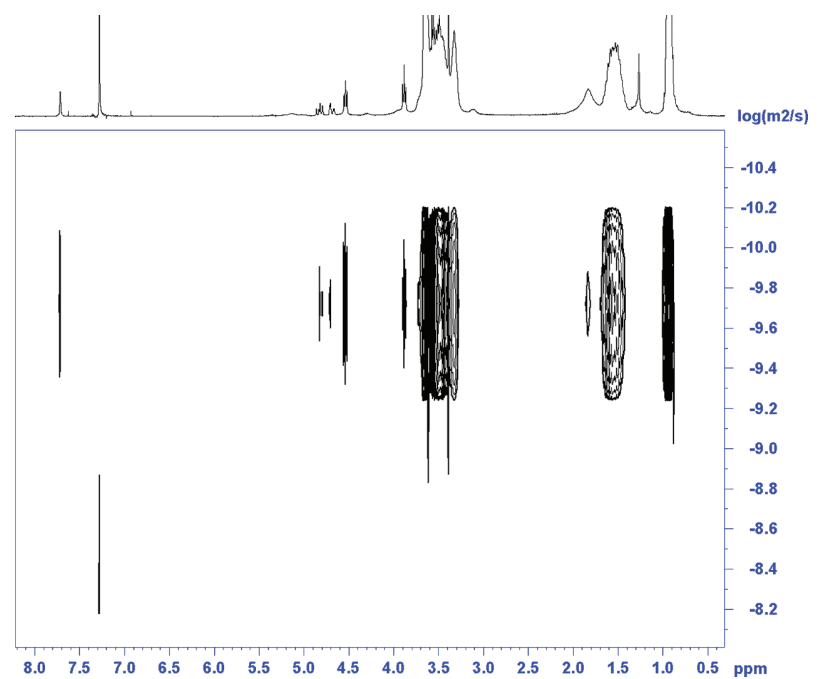

Figure 7. DOSY NMR spectrum of $\beta$-CD'-P(BO- $b$-EO $)_{14}$ star copolymer in deuterated chloroform.

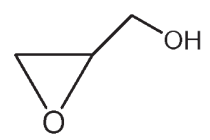

(a) Glycidol (GE)

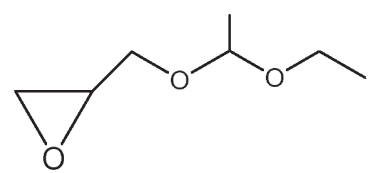

(b) Ethoxyethyl glycidyl ether (EEGE)
Scheme 3. Chemical structures of a) glycidol and b) ethoxyethyl glycidyl ether.

polymerization of EEGE followed by acidic cleavage of the protective group.

\subsubsection{Synthesis of 14-Arm Poly(Butylene Oxide-b-Ethoxyethylglycidyl} Ether) Star Copolymer ( $\beta$-CD'-P(BO-b-EEGE) $\left.{ }_{14}\right)$

Polymerization of EEGE was carried out in toluene, in the presence of $\mathrm{tBuP}_{4}$, using $\beta$-CD'- $\mathrm{PBO}_{14}$ star polymer as macroinitiator (Scheme 4). The experimental conditions and the results are presented in Table 3.

Conversion of the EEGE monomer was complete after $72 \mathrm{~h}$ of reaction at room temperature for each run. However, characterizations by SEC showed the simultaneous presence of linear and star polymers for all experiments. The linear polymers were the consequence of an initiation of the EEGE polymerization by traces of water present in the precursor star homopolymer, whatever the attempts to dry the macroinitiator. They did not result from side reactions, since no signal corresponding to allylic protons was observed between 5.30 and $6.50 \mathrm{ppm}$ (Figure 8). Despite various purification tests, we were unable to remove linear macromolecular chains. The SEC chromatogram of run 6 is shown in Figure 9.

The NMR molar masses given in Table 3 were not totally accurate because the NMR did not differentiate the star polymer from the linear polymer. The SEC $\bar{M}_{\mathrm{n}}$ value reported in Table 3 corresponds only to the star copolymer.

Despite the presence of linear chains in small amounts, the synthesis of 14-arm poly(butylene oxide-b-EEGE) star copolymer was characterized by the absence of transfer reaction and a narrow distribution of the molar masses, suggesting welldefined structures of the star copolymers.

\subsubsection{Deprotection of Hydroxy/ Groups of Ethoxyethylglycidyl Ether Units}

The synthesis of poly(butylene oxide-b-glycidyl ether) star copolymer could then be achieved by deprotection of hydroxyl groups of EEGE units. The deprotection, proceeding in two steps, was carried out with formic acid followed by basic hydrolysis of the intermediate in a dioxane/methanol mixture according to the procedure described in the literature. ${ }^{[50,51]}$ The synthetic pathway is shown in Scheme 5. The synthesis conditions and the results are summarized in Table 4.

The analysis of the Table 4 showed that the reaction time of the formic acid with the $\beta$-CD'-P(BO- $b$-EEGE) 14 precursor was a determining factor in the conversion of the EEGE units 

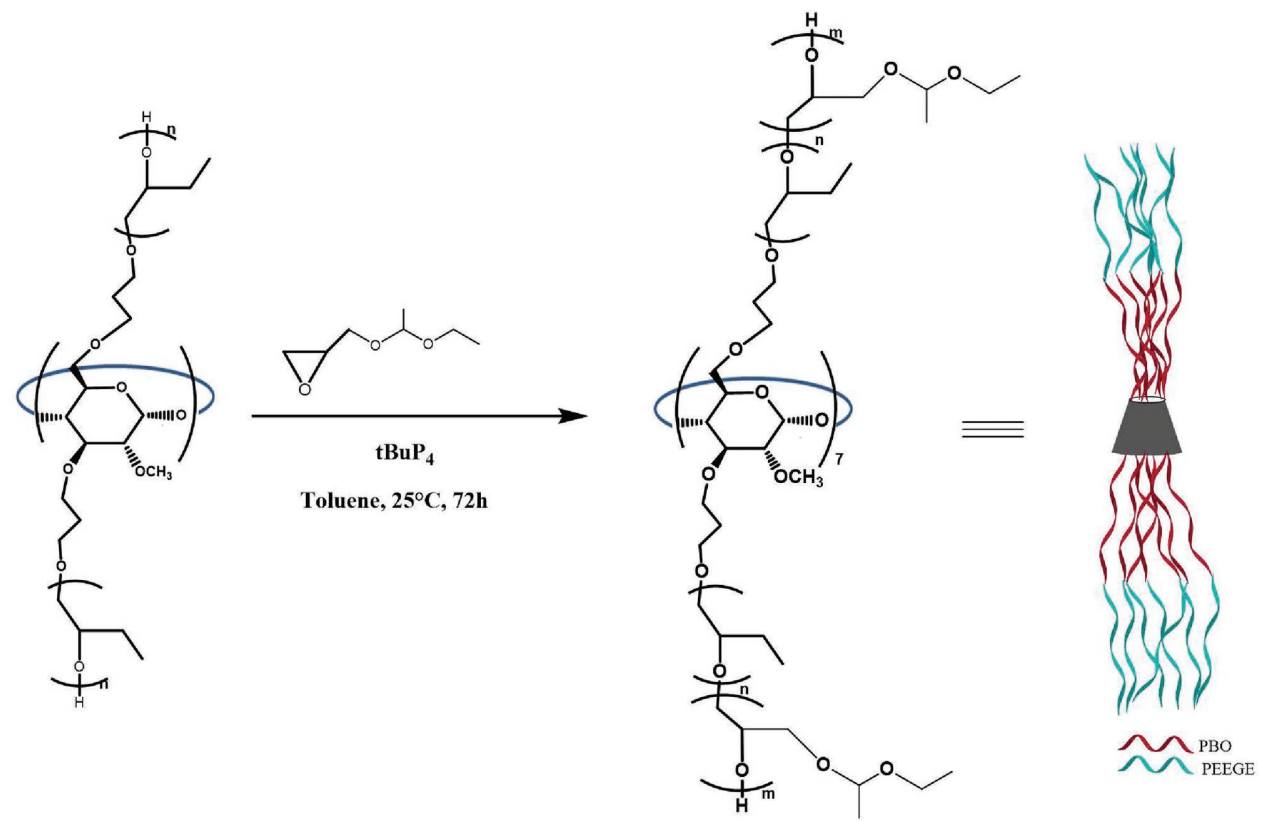

Scheme 4. Pathway route for the synthesis of $\mathrm{P}(\mathrm{BO}-b-\mathrm{EEGE})_{14}$ star copolymer.

to glycidyl ether units. Increasing this reaction time led to an increase in the degree of deprotection up to a total deprotection. Figure 10 shows ${ }^{1} \mathrm{H}$ NMR spectrum of run 12. A comparison of spectra in Figures 8 and 10 showed the disappearance of the characteristic signals of the acetal groups at 1.1-1.3 and $4.6 \mathrm{ppm}$.

Figure 11 shows the superposition of the SEC chromatograms of star copolymers $\beta$-CD'-P(BO- $b$-EEGE) 14 and $\beta$-CD'-P(BO- $b-\mathrm{GE})_{14}$ from run 6 and run 12 , respectively. A shift of the SEC trace of $\beta$-CD'-P(BO- $b-G E)_{14}$ toward the low molar masses was observed with respect to the SEC trace of $\beta$-CD'-P(BO- $b$-EEGE $)_{14}$, correlated with the expected result. Indeed, the modification of EEGE units to glycidyl ether units resulted in a molar mass decrease of $72 \mathrm{~g} \mathrm{~mol}^{-1}$ per unit. The disappearance of linear polymer chains was also noted and it is justified by the fact that, after deprotection, the resulting linear macromolecular chains (linear polyglycidol) were highly water soluble, then easily removed by dialysis. Thus, after the deprotection and purification steps, we observed a good agreement between the theoretical and final experimental molar masses of the star copolymers. The presence of aggregates was also observed in the SEC chromatogram of $\beta$-CD'-P(BO- $b-\mathrm{GE})_{14}$ as for the chromatogram of the amphiphilic copolymer $\beta$-CD'-P(BO- $b$-EO $)_{14}$ in Figure 6. The polymer of run 12 was characterized by DOSY NMR in $\mathrm{DMF}$ at $25{ }^{\circ} \mathrm{C}$. This analysis revealed a single diffusion coefficient whatever the NMR signal considered. The different signals led to similar values, as evidenced by the low value of the standard deviation of the diffusion coefficient $\left(\mathrm{D}=3.77 \pm 0.04 \cdot 10^{-11} \mathrm{~m}^{2} \mathrm{~s}^{-1}\right)$.
Table 3. Polymerizations of EEGE, initiated by $\beta-\mathrm{CD}^{\prime}-\mathrm{PBO}_{14}$, in the presence of $\mathrm{tBuP}_{4}$ in toluene at $25^{\circ} \mathrm{C}$ for $72 \mathrm{~h}$, with [EEGE] $=3 \mathrm{M}$.

\begin{tabular}{|c|c|c|c|c|c|c|c|c|}
\hline \multirow[t]{2}{*}{ Run } & \multirow[t]{2}{*}{ Macroinitiator } & \multirow{2}{*}{$\begin{array}{c}{[\mathrm{EEGE}] /} \\
{[\mathrm{OH}] /\left[\mathrm{P}_{4}\right]^{\mathrm{a})}}\end{array}$} & \multirow{2}{*}{$\begin{array}{l}\overline{M n}_{\text {Theo }^{\text {b) }}} \\
{\left[\mathrm{g} \mathrm{mol}^{-1}\right]}\end{array}$} & \multicolumn{3}{|c|}{ NMR } & \multicolumn{2}{|c|}{ SEC } \\
\hline & & & & $\begin{array}{c}\text { Conv }^{c)} \\
{[\%]}\end{array}$ & $\begin{array}{c}\overline{\left.\mathrm{Mn}^{\mathrm{c}}\right)} \\
{\left[\mathrm{g} \mathrm{mol}^{-1}\right]}\end{array}$ & $\overline{\left.X n / \mathrm{arm}^{\mathrm{c}}\right)}$ & $\overline{D^{d)}}$ & $\begin{array}{c}\overline{\left.M^{\mathrm{d}}\right)} \\
{\left[\mathrm{g} \mathrm{mol}^{-1}\right]}\end{array}$ \\
\hline 6 & $\begin{array}{c}\text { Run } 2 \\
\left.\left(8100 \mathrm{~g} \mathrm{~mol}^{-1}\right)^{\mathrm{c}}\right)\end{array}$ & $15 / 1 / 0.2$ & 38750 & 100 & 46900 & 19 & 1.13 & 27700 \\
\hline 7 & $\begin{array}{c}\text { Run } 4 \\
\left(9100 \mathrm{~g} \mathrm{~mol}^{-1}\right)^{\mathrm{c})}\end{array}$ & $15 / 1 / 0.2$ & 39750 & 100 & 50000 & 20 & 1.13 & 16700 \\
\hline 8 & $\begin{array}{c}\text { Run } 2 \\
\left(8100 \mathrm{~g} \mathrm{~mol}^{-1}\right)^{\mathrm{c})}\end{array}$ & $10 / 1 / 0.2$ & 28540 & 100 & 32600 & 12 & - & - \\
\hline
\end{tabular}

a) Molar ratio Monomer/Initiator/Phosphazene Base; b) $\overline{M n}$ theoretical = Conversion $(\mathrm{NMR}) \times$ Monomer molar eq. $\times \mathrm{M}$ (monomer) $+\mathrm{M}$ (initiator); ${ }^{\mathrm{c})}$ Determined by NMR; ${ }^{\mathrm{d})} \mathrm{SEC}$ in DMF, calibration with PMMA; - means not determined.

\subsection{Interactions of $\beta$-CD Derivatives with Lipid Membranes}

The ability for the initiator and the star polymers to interact with lipid bilayers and to form artificial channels was investigated by electric measurements, via the "Black Lipid Membrane" (BLM) technique. ${ }^{[28]}$ This technique consists in measuring the current through a model lipid membrane as a function of time, for an applied voltage. Perturbation of the membrane, due to the presence of a (macro)molecule able to perturb or interact with it, leads to the appearance of a current. Data analysis, giving mainly the current distribution (occurrence vs current), allows us to characterize the 


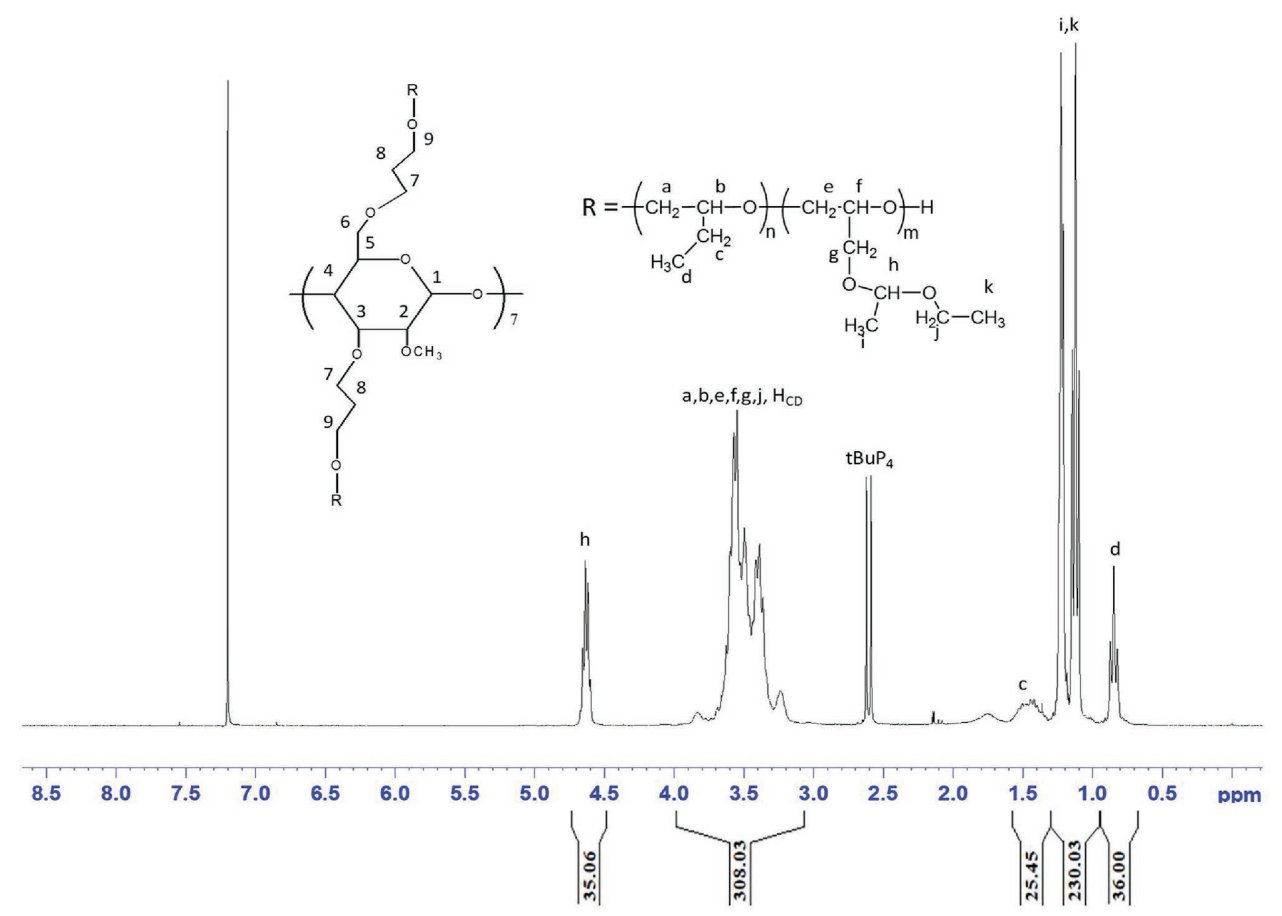

Figure 8. ' $\mathrm{H}$ NMR spectrum of $\beta-C D$ '- $\mathrm{P}(B \mathrm{BO}-\mathrm{b}-\mathrm{EEGE})_{14}$ star copolymer in deuterated chloroform.

type of interactions existing between the studied (macro) molecule and the lipid bilayer (well-defined nanochannels, ill-defined interactions, aggregates, etc.).

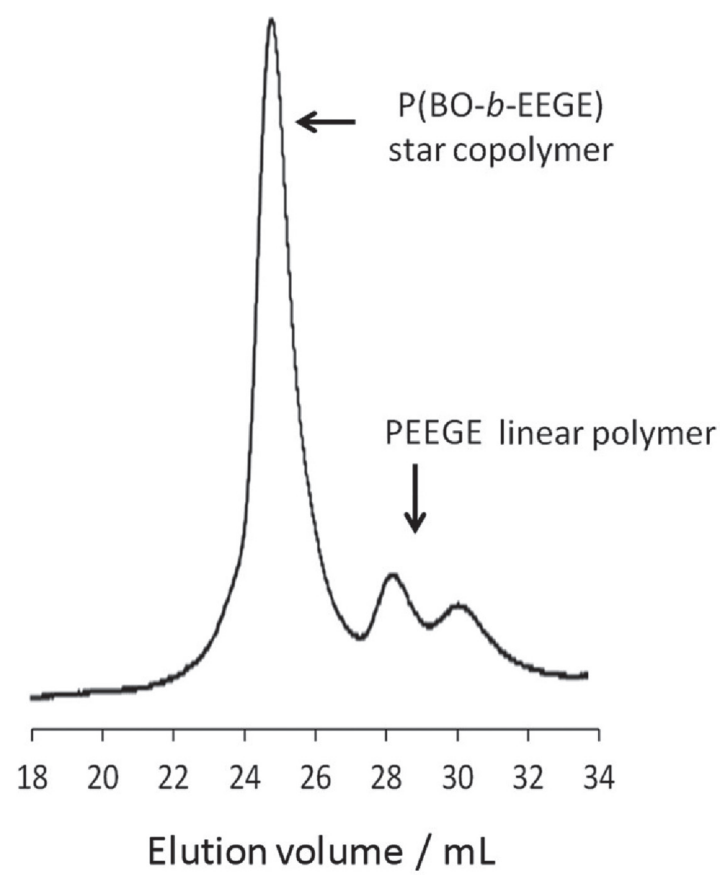

Figure 9. SEC chromatogram of $\beta$-CD'-P(BO-b-EEGE $)_{14}$ star copolymer (run 6, Table 3) in DMF.

\subsubsection{Interactions of $\beta-\mathrm{CD}^{\prime} \mathrm{OH}_{14}$ with a Lipid Bilayer}

First, the interactions of the initiator with lipid bilayers were investigated. $\beta$-CD derivatives could self-assembly and induce artificial channel formation, ${ }^{[27,28,52,53]}$ as established also for peptidebased channels. ${ }^{[5,55]}$ However, whatever the used concentration of $\beta$ - $\mathrm{CD}^{\prime} \mathrm{OH}_{14}$ introduced in both chambers of the BLM set-up, no current change was detected (Figure S18, Supporting Information): there is no artificial channel formation with $\beta-\mathrm{CD}^{\prime} \mathrm{OH}_{14}$.

\subsubsection{Interactions of $\beta-C D^{\prime}-P B O_{14}$ with a Lipid Bilayer}

Then, the ability of the hydrophobic star polymer $\beta$-CD'- $\mathrm{PBO}_{14}$ to form artificial channels was investigated. Figure S19, Supporting Information presents the current versus time traces, and their analyses, obtained when $\beta$-CD'-PBO 14 was added at concentrations of 120 and $12 \mathrm{nM}$, in both chambers of the BLM set $u p$, at $\mathrm{pH}=7$. These concentrations were chosen based on previously reported results. ${ }^{[28]}$

Figure S19A, Supporting Information shows the current versus time trace obtained for a $\beta$-CD'- $\mathrm{PBO}_{14}$ concentration of $120 \mathrm{~nm}$ and for an applied voltage of $-100 \mathrm{mV}$. The recorded current intensities ranged from -20 to $-80 \mathrm{pA}$, witnessing that the hydrophobic star polymer interacts with the lipid membrane. However, no discrete signal was observed. The occurrence of the events was then plotted as a function of the measured current (Figure S19B, Supporting Information). No peak was observed in the distribution, but a diffuse signal tailing toward the large currents was obtained. We conclude that no well-defined artificial channel was formed in this experiment. 

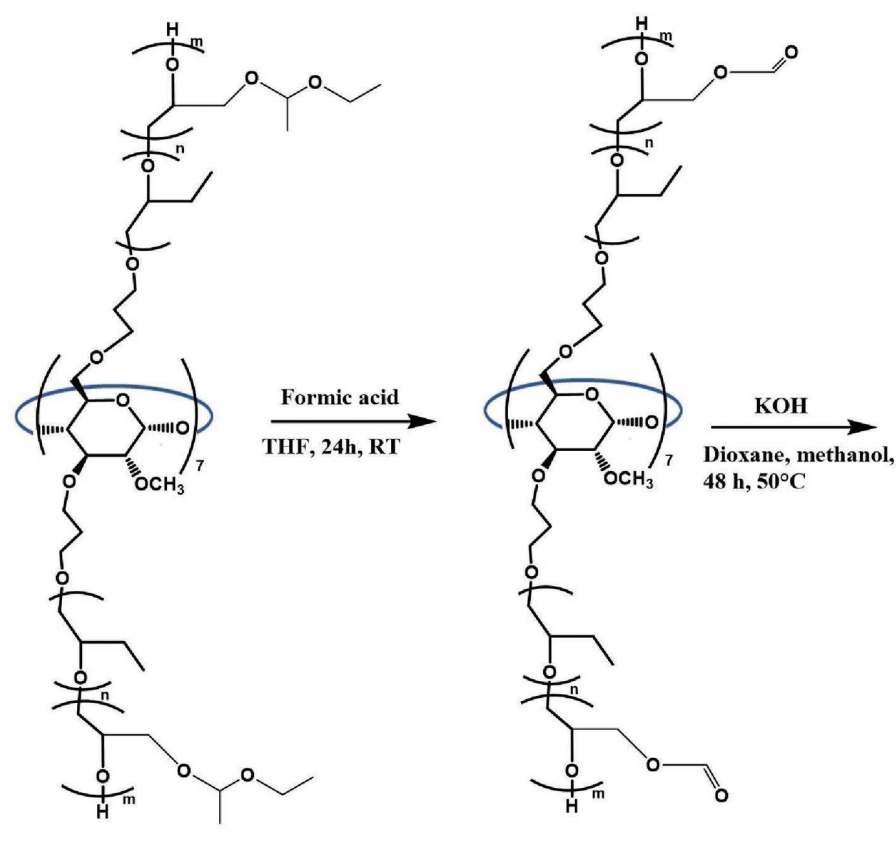

Scheme 5. Pathway route for the synthesis of $\beta-C D^{\prime}-P(B O-b-G E)_{14}$.

The concentration of $\beta$-CD'- $\mathrm{PBO}_{14}$ in the chambers was then decreased to $12 \mathrm{~nm}$ and the current versus time trace was reported (Figure S19C, Supporting Information). Discrete 1 pA current jumps were observed after $700 \mathrm{~s}$ for an applied voltage of $100 \mathrm{mV}$. This intensity value is comparable with the one previously reported for monomolecular star polymer CDbased artificial channels. ${ }^{[27,28,52]}$ The analysis of the current distribution (Figure S19D, Supporting Information) shows a well-defined distribution of three main current peaks $(0 \mathrm{pA}$ for the membrane, $-1 \mathrm{pA}$ for a current jump, and $-5 \mathrm{pA})$. The largest current peak could be attributed either to simultaneous multiple artificial channel insertion in the lipid bilayer or to aggregate insertion. No evidence concerning the discrimination between those assumptions can be provided at this stage.

It has to be noticed that the detection of the formation of monomolecular artificial channels was carried out at a concentration below the one previously reported for CD-based star polymers $\left(200 \mathrm{~nm}\right.$ in case of $\beta$-CD'-PEO $\left.{ }_{14}\right) \cdot{ }^{[28]}$ We attributed this reduced active concentration to a better fit between

Table 4. Operating conditions for synthesis of $\beta$-CD'-P(BO- $b-\mathrm{GE})_{14}$ amphiphilic star copolymers.

\begin{tabular}{|c|c|c|c|c|c|c|c|c|}
\hline \multirow[t]{2}{*}{ Run } & \multirow{2}{*}{$\begin{array}{c}\beta \text {-CD'-P(BO- } \\
b \text {-EEGE) }{ }_{14} \\
\text { precursor }^{\text {a) }}\end{array}$} & \multirow{2}{*}{$\begin{array}{l}\text { React with } \\
\text { formic acid } \\
25^{\circ} \mathrm{C}\end{array}$} & \multirow{2}{*}{$\begin{array}{l}\text { React with } \\
\mathrm{KOH} \\
50^{\circ} \mathrm{C}\end{array}$} & \multirow{2}{*}{$\begin{array}{l}\mathrm{DD}^{\mathrm{b})} \\
{[\%]}\end{array}$} & \multirow{2}{*}{$\begin{array}{c}\overline{M n}_{\mathrm{th}} \\
{\left[\mathrm{g} \mathrm{mol}^{-1}\right]}\end{array}$} & \multirow{2}{*}{$\begin{array}{c}\overline{M n}_{\mathrm{RMN}} \\
{\left[\mathrm{g} \mathrm{mol}^{-1}\right]}\end{array}$} & \multicolumn{2}{|c|}{ SEC } \\
\hline & & & & & & & $\bigoplus$ & $\overline{M n}\left[\mathrm{~g} \mathrm{~mol}^{-1}\right]$ \\
\hline 9 & Run 6 & $4 \mathrm{~h}$ & $48 \mathrm{~h}$ & 36 & - & - & - & - \\
\hline 10 & Run 6 & $12 \mathrm{~h}$ & $48 \mathrm{~h}$ & 74 & - & - & - & - \\
\hline 11 & Run 8 & $24 \mathrm{~h}$ & $48 \mathrm{~h}$ & 100 & 18460 & 13300 & 1.11 & 14500 \\
\hline 12 & Run 6 & $24 \mathrm{~h}$ & $48 \mathrm{~h}$ & 100 & 23630 & 26750 & 1.11 & 20750 \\
\hline
\end{tabular}

a) Run 6 (46900 $\left.\mathrm{g} \mathrm{mol}^{-1}\right)$, Run 8 (32600 $\mathrm{g} \mathrm{mol}^{-1}$ ) of Table $3, \overline{\mathrm{Mn}}$ determined by NMR; b)SEC in DMF, calibration with PMMA; DD, degree of deprotection determined by NMR; - means not determined. the hydrophobic part of the lipid bilayer and the one of $\beta$-CD'-PBO 14 . The artificial channel lifetime of $\beta$-CD'- $\mathrm{PBO}_{14}$ was observed in the minute range, and no pulling out of the artificial channels was detected. However, the hydrophobic nature of $\beta$-CD'- $\mathrm{PBO}_{14}$ is a drawback, since the only way to use this star polymer was to use THF as solvent.

\subsubsection{Interactions of $\beta-C D$ '-P(BO- $b-E O){ }_{14}$ with a Lipid Bilayer}

The amphiphilic copolymer $\beta$-CD'-P(BO- $b$-EO $)_{14}$ was then studied by the BLM technique, at a concentration of $6 \mathrm{~nm}$, in both chambers of the BLM set up, at $\mathrm{pH}=7$. Figure 12 shows the resulting current versus time traces and the analysis of those experiments, performed on two membranes, in order to check the repeatability of the experiments.

Figure 12A shows the current versus time trace obtained for the first experiment, the current intensities ranging from -1 to $-15 \mathrm{pA}$, for an applied voltage of $-100 \mathrm{mV}$. Discrete/defined current jumps were observed from $1200 \mathrm{~s}$. We attributed those events to the insertion of the amphiphilic copolymer in the lipid membrane. The insertion and the formation of artificial channels were also confirmed by the analysis of the current distribution, showing discrete peaks on the distribution (Figure 12B). Plotting the maximum current peak versus whole number, defined as suspected number of artificial channels inserted at the same time of Figure 12B, one observed a linear relationship between number of inserted artificial channels and current, giving a unitary current of $-1 \mathrm{pA}$, 


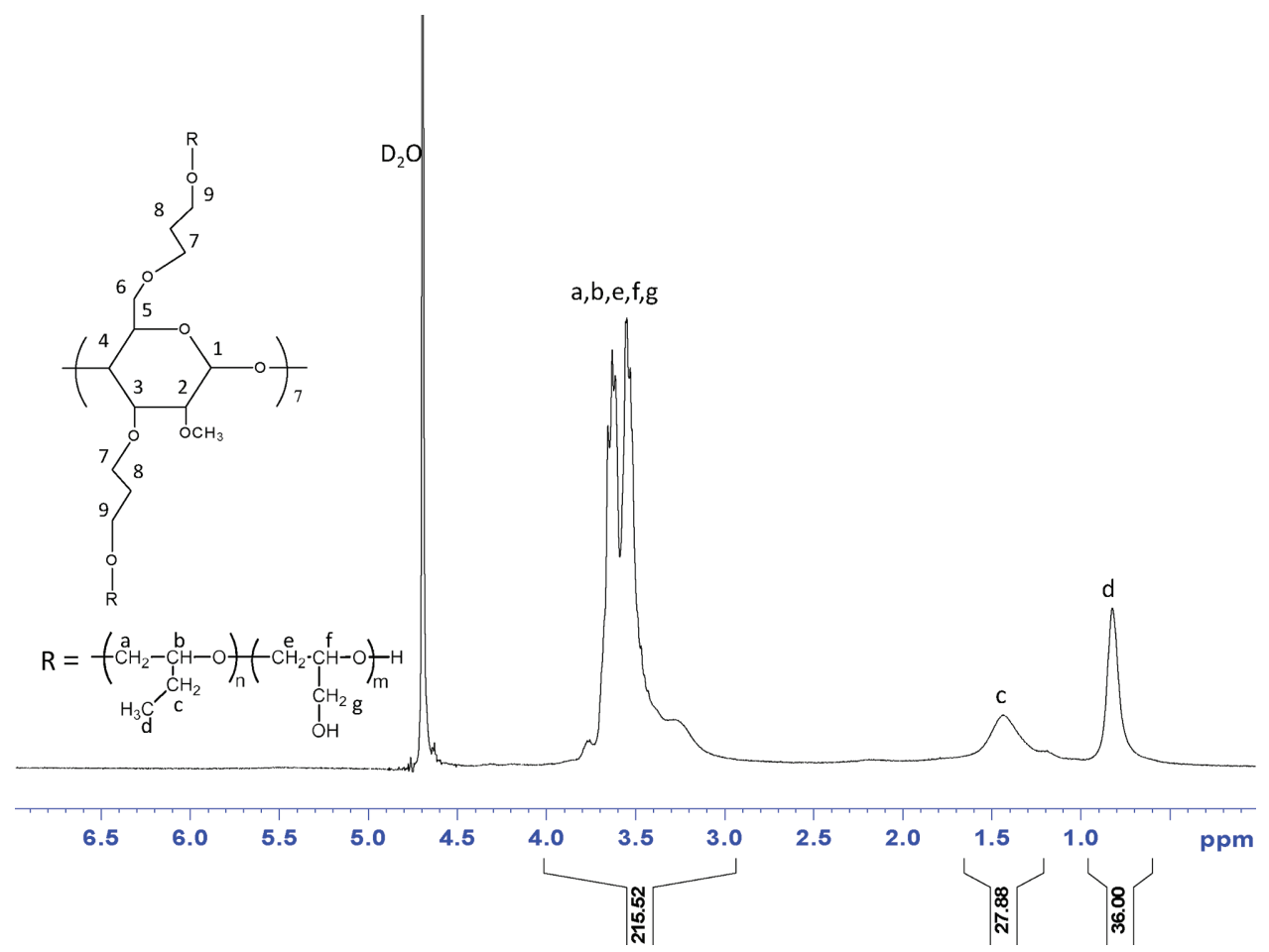

Figure 10. ' $\mathrm{H}$ NMR spectrum of $\beta$-CD'-P(BO-b-GE) 14 amphiphilic star copolymer (run 12, Table 4) in deuterium oxide.

for an applied voltage of $-100 \mathrm{mV}$ (Figure 12E). Figure 12C,D, obtained with another membrane, confirmed the formation of artificial channels (unitary current of $-0.8 \mathrm{pA}$ for $-100 \mathrm{mV}$ ), even if the artificial channel lifetime was not reproducible (seconds in Figure 12C vs 10 min in Figure 12A).

As reported for $\beta$-CD'- $\mathrm{PBO}_{14}$, the used concentration to observe the artificial channel formation was around 30 times lower than the one used for other CD-based star polymers

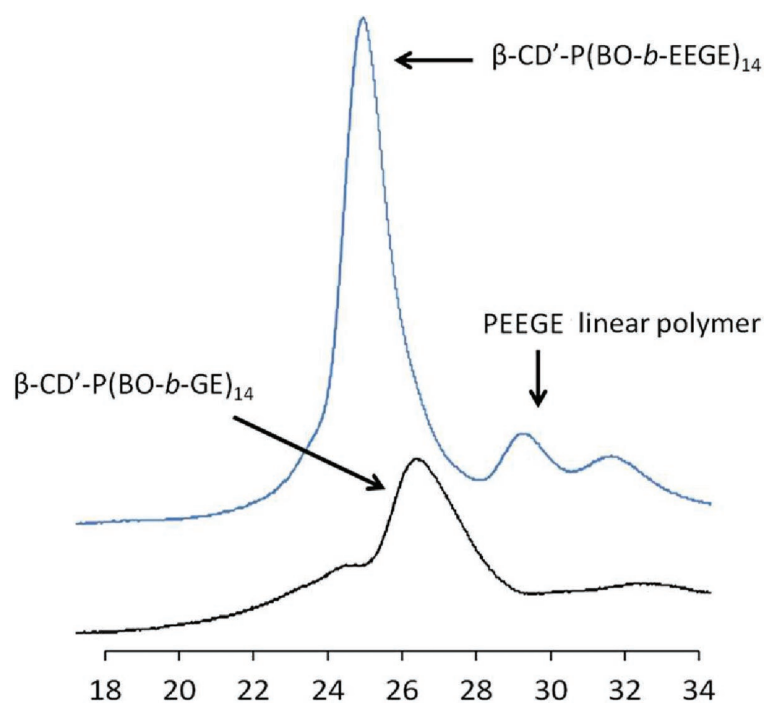

Figure 11. Superposition of SEC chromatograms of $\beta-C D^{\prime}-\mathrm{P}(B O-b-G E)_{14}$ and $\beta$-CD'-P(BO-b-EEGE) 14 .
(200 nм for $\beta$-CD'-PEO 14 ), which tends to confirm the advantage of using CD-based star polymers with a hydrophobic domain having a size that fits with the hydrophobic part of the lipid bilayer. Adding a PEO hydrophilic block on each branch of the star polymer allowed to obtain hydrosoluble artificial channels and facilitated their use for further applications.

\subsubsection{Interactions of $\beta-C D^{\prime}-P(B O-b-G E)_{14}$ with a Lipid Bilayer}

We decided then to investigate the influence of the chemical nature of hydrophilic blocks of the star polymer on the artificial channel formation, PEO block being replaced by PGE block. Two star copolymers were then studied. $\beta$-CD'-P(BO- $b$-GE $)_{14}$ with an average of 6 units of GE per branch was first used. This number of monomer units allowed to reach a mean molar mass of PGE hydrophilic block equivalent to the one of PEO in $\beta$-CD'-P(BO- $b$-EO $)_{14} \cdot \beta$-CD'-P(BO- $b$-GE $)_{14}$ with an average of 18 units of GE per branch was then used to investigate the effect of molar mass.

Figure S20, Supporting Information presents the current versus time traces, and their corresponding current distributions, obtained when $\beta$-CD'-P(BO- $b-\mathrm{GE})_{14}$ (with 6 units of GE) was used at a concentration of $7 \mathrm{~nm}$, in both chambers of the BLM set up, at $\mathrm{pH}=7$, for two different membranes. For both experiments, the obtained current intensities ranged from -1 to $-100 \mathrm{pA}$, for an applied voltage of $-100 \mathrm{mV}$ (Figure S20A-D, Supporting Information). The corresponding histograms of current distribution (Figure S20B-E, Supporting Information) showed no clear peak in the distribution, but a diffuse 

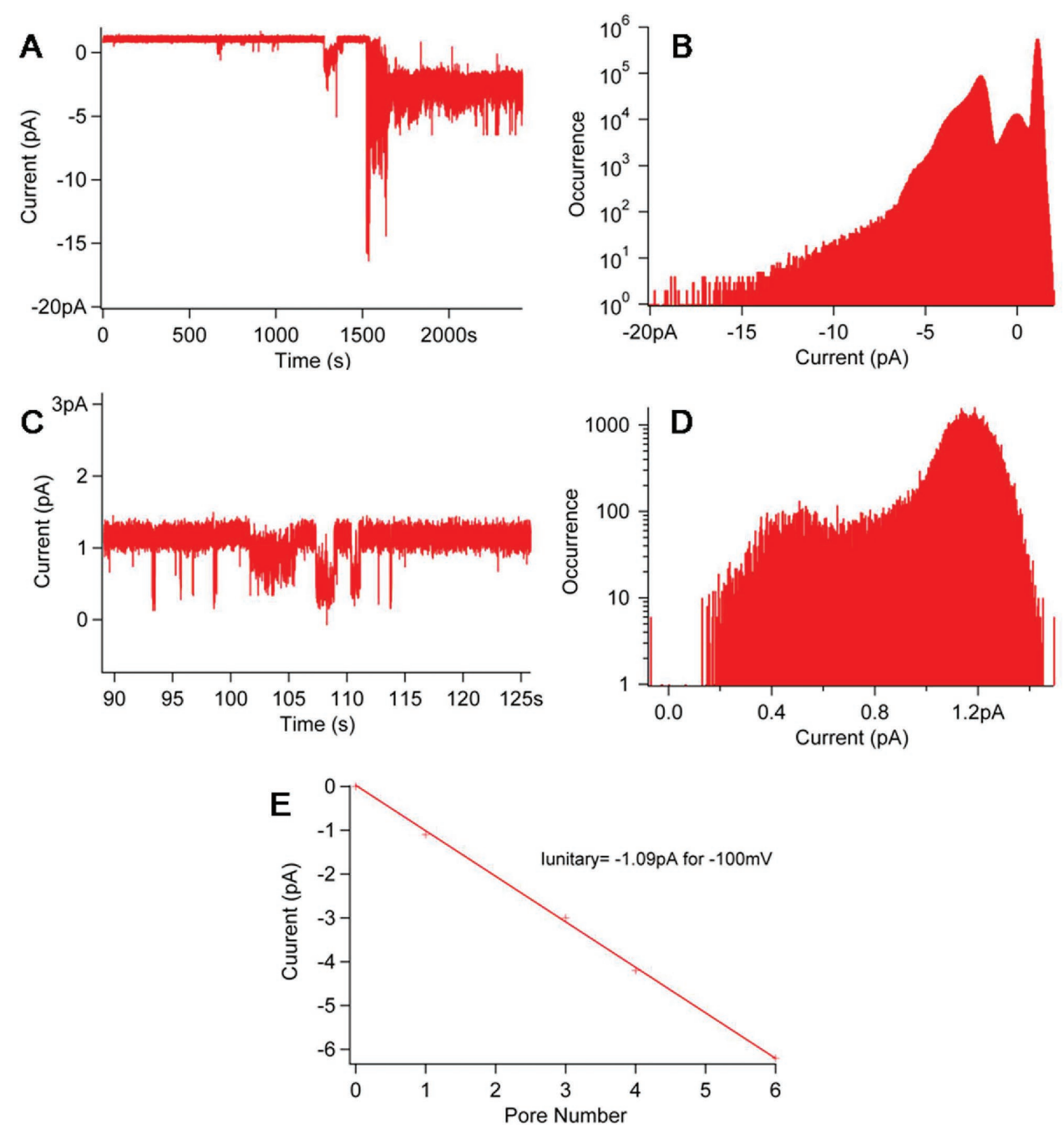

Figure 12. Monomolecular artificial channels formed by $\beta$-CD'-P(BO- $b$-EO $)_{14}$. $(\mathrm{V}=-100 \mathrm{mV},[\mathrm{KCl}]=1 \mathrm{~m}, 6 \mathrm{~nm})$. A,C) Current versus time. B,D) Corresponding current distribution. E) Current versus number of pores.

tailing toward the large currents. We concluded the presence of ill-defined events, even if the insert Figure S20C, Supporting Information showed discrete current jumps, that we attributed to the formation of monomolecular artificial channels. In the used conditions, it has to be noticed that the star polymer was poorly soluble in water.

Figure 13 presents the current versus time traces, and their corresponding analyses, obtained with $\beta$-CD'-P(BO- $b-\mathrm{GE})_{14}$ (with 18 units of GE) in the presence of lipid bilayer, at a concentration of $4 \mathrm{~nm}$, in both chambers of the BLM set up, at $\mathrm{pH}=7$, for an applied voltage of $-100 \mathrm{mV}$, for three distinct experiments.

Figure 13A shows a discrete current jump, lasting $100 \mathrm{~s}$, whose value was evaluated with the current distribution (Figure 13B). The corresponding current intensity of $-1 \mathrm{pA}$ was in accordance with the current value already discussed in the case of $\beta$-CD'-P(BO- $b$-GE $)_{14}$ with 6 units of GE. However, Figure 13C-F presents long-lasting discrete current jumps: one with a current value of $-4.5 \mathrm{pA}$, for at least $27 \mathrm{~min}$ (from 400 to $2000 \mathrm{~s}$-end of recording, Figure $13 \mathrm{C}-\mathrm{E}$ ) and another one with a current value of $-3.1 \mathrm{pA}$, for at least $18 \mathrm{~min}$ (from 100 to $1100 \mathrm{~s}$-end of recording, Figure $13 \mathrm{~F}, \mathrm{G})$. Those two current values were different from each other and also different from the current value obtained with $\beta$-CD'-P(BO- $b$-GE $)_{14}$ with 6 units of GE, that was not expected. We assumed the formation of stable permeation structures which are different from monomolecular artificial channels, but nevertheless welldefined permeation structures. The obtained permeation thus lasted longer than that of the insertion of $\beta$-CD'-P(BO- $b-\mathrm{GE})_{14}$ with 6 units of GE. The increase of the hydrophilic PGE block length seems to improve the ability of the amphiphilic copolymer to form artificial channels.

To summarize these results, $\beta$-cyclodextrin star copolymers are able to form artificial channels. Adding hydrophobic block to the core of the star polymers, fitting with the size of the lipid bilayer, allows longer insertion times for the artificial channels, whose activity was observed at a much lower concentration value than the one used for their counterpart without hydrophobic part. Adding hydrophilic blocks allows to obtain hydrosoluble artificial channels. 

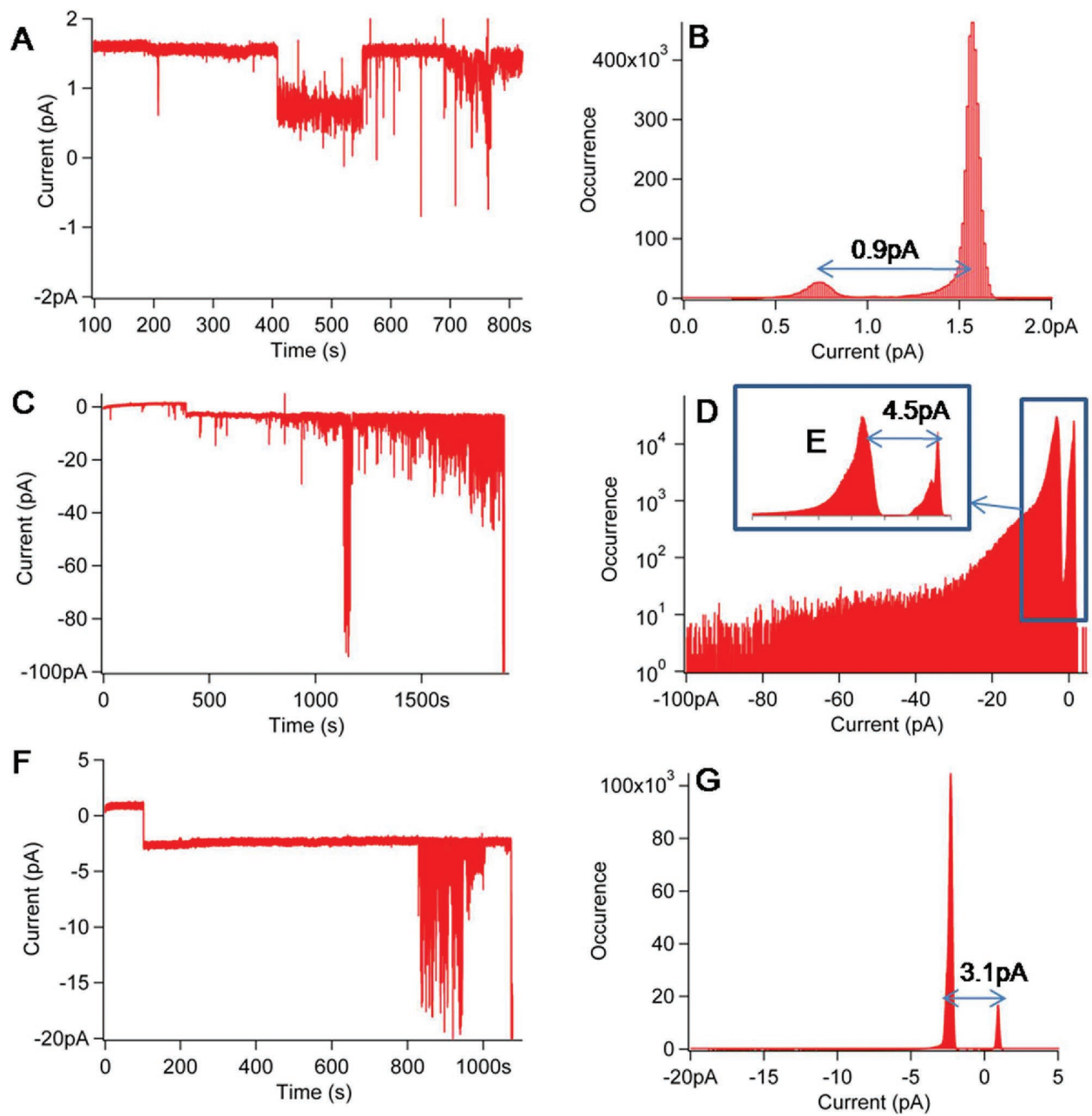

Figure 13. Behavior of $\beta$-CD'-P(BO- $b-G E)_{14}$ with 18 units of $G E$ in presence of lipid bilayer $(V=-100 \mathrm{mV},[K C l]=1 \mathrm{M}, 4 \mathrm{~nm})$. $\left.A, C, F\right)$ Current versus time. $B, D, G)$ Corresponding occurrence versus current. E) Zoom of current distribution (D).

\section{Conclusions}

Due to their attractive properties, research on star polymers is still current and intensive. In this paper, we investigated different pathways to synthesize amphiphilic star block copolymers with a hydrophobic center composed of butylene oxide units. The number of polymerized butylene oxide units was low, about seven, in agreement with required conditions for the synthesis of artificial channels. First, the anionic ringopening polymerization of 1,2-butylene oxide (BO) initiated by $\quad$ per(2-O-methyl-3,6-di-O-(3-hydroxypropyl))- $\beta$-cyclodextrin and catalyzed by $\mathrm{tBuP}_{4}$ in $\mathrm{DMF}$ was investigated. The control of the polymerization was achieved, making the synthesis of 14-arm star poly(butylene oxide)s $\left(\beta\right.$-CD'-PBO $\left.{ }_{14}\right)$ possible with well-defined structures. These polymers were then used to synthesize two kinds of amphiphilic star block copolymers: 14-arm poly(butylene oxide-b-ethylene oxide) star and 14-arm poly(butylene oxide-b-glycidol) star. The first star copolymer was successfully obtained thanks to a Huisgen cycloaddition between an $\alpha$-methoxy- $\omega$-azidopoly(ethylene oxide) and propargyl group-functionalized $\beta$-CD'- $\mathrm{PBO}_{14}$ ("grafting-onto" strategy). Different coupling reactions between $\beta$-CD’-PBO ${ }_{14}$ and PEO chains having mesylate or iodide end-chains were tested. However, the reactivity of these functions was not high enough in the tested experimental conditions to allow the synthesis of well-defined star polymers. The last amphiphilic star block copolymer, the 14-arm poly(butylene oxide-b-glycidol) star, was synthesized using $\beta$-CD'- $\mathrm{PBO}_{14}$ as macroinitiator according to a "core-first" method and $\mathrm{tBuP}_{4}$ as catalyst. In this pathway, it was necessary to use the epoxide monomer under a protected form in order to avoid the formation of hyperbranched oligomers due to intra- and inter-transfer reactions. Thus, the EEGE was synthesized by protecting glycidol with ethyl vinyl ether. After the EEGE polymerization performed in toluene, an acidic cleavage of the protective groups was performed and allowed the synthesis of new well-defined amphiphilic star copolymers.

The initiator and the star polymers were finally evaluated as artificial channels in lipid membranes, by electric measurements. Fitting the hydrophobic domain of the star polymers with the hydrophobic part of the lipid bilayer reduced the active concentration to witness the interactions between the star polymers and the lipid membrane. Formation of long-lasting monomolecular artificial channels was demonstrated for hydrophobic 
$\beta$-CD'-PBO ${ }_{14}$ and amphiphilic $\beta$-CD'-P(BO- $b$-EO $)_{14}$ and $\beta$-CD'$\mathrm{P}(\mathrm{BO}-b-\mathrm{GE})_{14}$. Adding a hydrophilic block PEO or PGE on each branch of the star polymer allowed us to obtain hydrosoluble artificial channels, important aspect to develop further applications. The increase of the hydrophilic PGE block length (18 units), compared to the one with the six glycidol repeat units, seemed to improve the ability of the amphiphilic copolymers to form artificial channels.

\section{Supporting Information}

Supporting Information is available from the Wiley Online Library or from the author.

\section{Conflict of Interest}

The authors declare no conflict of interest.

\section{Keywords}

$\beta$-cyclodextrin, amphiphilic star copolymers, anionic polymerization, artificial channels, phosphazene base
[18] L. Szente, J. Szejtli, Trends Food Sci. Technol. 2004, 15, 137.

[19] K. Uekama, F. Hirayama, T. Irie, Chem. Rev. 1998, 98, 2045.

[20] H.-J. Buschmann, E. Schollmeyer, J. Cosmet Sci. 2002, 53, 185.

[21] N. Badi, P. Guégan, F.-X. Legrand, L. Leclercq, S. Tilloy, E. Monflier, J. Mol. Catal. A: Chem. 2010, 318, 8.

[22] K. M. Xiu, J. J. Yang, N. N. Zhao, J. S. Li, F. J. Xu, Acta Biomater. 2013, 9, 4726.

[23] X. Chen, W. Wu, Z. Guo, J. Xin, J. Li, Biomaterials 2011, 32, 1759.

[24] J. Bai, X. Wang, P. Fu, Z. Cui, Q. Zhao, X. Pang, M. Liu, RSC Adv. 2015, 5, 96785.

[25] B. J. Busche, A. E. Tonelli, C. M. Balik, Polymer 2010, 51, 454.

[26] C.-g. Mu, X.-d. Fan, W. Tian, Y. Bai, X. Zhou, Polym. Chem. 2012, 3, 1137.

[27] N. Badi, L. Auvray, P. Guegan, Adv. Mater. 2009, 21, 4054.

[28] Y. El Ghoul, R. Renia, I. Faye, S. Rassou, N. Badi, V. BennevaultCelton, C. Huin, P. Guegan, Chem. Commun. 2013, 49, 11647.

[29] N. Madhavan, E. C. Robert, M. S. Gin, Angew. Chem., Int. Ed. 2005, 44, 7584.

[30] A. Alsbaiee, B. J. Smith, L. Xiao, Y. Ling, D. E. Helbling, W. R. Dichtel, Nature 2016, 529, 190.

[31] Y. Pan, Y. Xue, J. Snow, H. Xiao, Macromol. Chem. Phys. 2015, 216, 511.

[32] A. O. Fitton, J. Hill, D. E. Jane, R. Millar, Synthesis 1987, 1987, 1140.

[33] V. Bennevault-Celton, A. Urbach, O. Martin, C. Pichon, P. Guégan, P. Midoux, Bioconjugate Chem. 2011, 22, 2404.

[34] M. Holz, H. Weingartner, J. Magn. Reson. (1969) 1991, 92, 115.

[35] T. Isono, K. Kamoshida, Y. Satoh, T. Takaoka, S.-i. Sato, T. Satoh, T. Kakuchi, Macromolecules 2013, 46, 3841.

[36] S. Boileau, in Comprehensive Polymer Science and Supplements (Ed: J. C. Bevington), Pergamon, Amsterdam 1989, p. 467.

[37] R. Francis, D. Taton, J. L. Logan, P. Masse, Y. Gnanou, R. S. Duran, Macromolecules 2003, 36, 8253.

[38] X. Feng, D. Taton, E. Ibarboure, E. L. Chaikof, Y. Gnanou, J. Am. Chem. Soc. 2008, 130, 11662.

[39] S. Glanzer, K. Zangger, Chem. Eur. J. 2014, 20, 11171.

[40] G. Pereira, C. Huin, S. Morariu, V. Bennevault-Celton, P. Guégan, Aust. J. Chem. 2012, 65, 1145.

[41] H. Gao, K. Matyjaszewski, Macromolecules 2006, 39, 4960.

[42] T. Higashihara, S. Ito, S. Fukuta, S. Miyane, Y. Ochiai, T. Ishizone, M. Ueda, A. Hirao, ACS Macro Lett. 2016, 5, 631.

[43] H. Woo, H. Kang, A. Kim, S. Jang, C. J. Park, S. Park, B.-S. Kim, H. Song, H. K. Park, Molecules13235, 2012, 17.

[44] P. Thirumurugan, D. Matosiuk, K. Jozwiak, Chem. Rev. 2013, 113, 4905.

[45] M. van Dijk, D. T. S. Rijkers, R. M. J. Liskamp, C. F. van Nostrum, W. E. Hennink, Bioconjugate Chem. 2009, 20, 2001.

[46] V. Crupi, D. Majolino, P. Migliardo, V. Venuti, N. Micali, V. Villari, P. Mineo, D. Vitalini, E. Scamporrino, J. Mol. Struct. 2003, 651-653, 675.

[47] S. Peleshanko, J. Jeong, R. Gunawidjaja, V. V. Tsukruk, Macromolecules 2004, 37, 6511.

[48] B. R. Spears, M. A. Marin, J. R. Montenegro-Burke, B. C. Evans, J. McLean, E. Harth, Macromolecules 2016, 49, 2022.

[49] A. Thomas, S. S. Müller, H. Frey, Biomacromolecules 2014, 15, 1935.

[50] D. Taton, A. Le Borgne, M. Sepulchre, N. Spassky, Macromol. Chem. Phys. 1994, 195, 139.

[51] A. Sunder, H. Frey, R. Mülhaupt, Macromol. Symp. 2000, 153, 187.

[52] L. Bacri, A. Benkhaled, P. Guégan, L. Auvray, Langmuir 2005, 21, 5842.

[53] J. K. W. Chui, T. M. Fyles, Org. Biomol. Chem. 2014, 12, 3622.

[54] M. R. Ghadiri, J. R. Granja, L. K. Buehler, Nature 1994, 369, 301.

[55] M. Danial, C. M.-N. Tran, K. A. Jolliffe, S. Perrier, J. Am. Chem. Soc.

2014, 136, 8018 .
[17] S. Rassou, N. Illy, O. Tezgel, P. Guégan, J. Polym. Sci., Part A: Polym. Chem. 2018, 56, 1091. 